\title{
IMPLEMENTACIÓN DEL DERECHO DE CONSULTA DE LOS PUEBLOS INDÍGENAS Y SUS ASPECTOS AMBIENTALES EN CHILE A LA LUZ DEL CONVENIO No 169 DE LA OIT
}

\section{Caso del Decreto Supremo 124/2009 que crea el reglamento sobre consulta*}

\author{
MARCOS JAVIER RÍOS ANGULO** \\ Becario de investigación \\ Universitat Rovira i Virgili \\ marcos.rios@urv.cat
}

Recibido: 26 de octubre de 2011 / Aceptado: 5 de diciembre de 2010

\begin{abstract}
RESUMEN: El Decreto Supremo $N^{\circ} 124$ de 25 de septiembre de 2009 crea el Reglamento sobre consulta y participación de pueblos indígenas, implementando el Convenio OIT $N^{\circ} 169$ en Chile. En esta nota se analizan los aspectos ambientales del Decreto, la concordancia con los estándares internacionales del derecho de los pueblos indígenas y el nivel de implementación en el nuevo marco institucional ambiental chileno.
\end{abstract}

RESUM: El Decret Suprem N 124 de 25 de setembre de 2009 crea el Reglament sobre consulta i participació de pobles indígenes, implementant el Conveni OIT $\mathrm{N}^{\circ} 169$ a Xile. En aquesta nota s'analitzen els aspectes ambientals del Decret, la concordança amb els estàndards internacionals del dret dels pobles indígenes, i el nivell d'implementació en el nou marc institucional ambiental xilè.

\footnotetext{
* Investigación realizada con el apoyo del Instituto Catalán Internacional por la Paz.

** Becario predoctoral del Instituto Catalán Internacional por la Paz (FI-ICIP), contratado en calidad de personal investigador novel adscrito al Departamento de Derecho Público de la Universitat Rovira i Virgili (URV).
} 
ABSTRACT: Supreme Decree No. 124 of 25 September 2009 creates the Regulation on consultation and participation of indigenous peoples, implementing ILO Convention No. 169 in Chile. This paper examines the environmental aspects of the decree, the agreement with the international standards of rights of indigenous peoples, and the level of implementation in the new Chilean environmental institutional framework.

PALABRAS CLAVE: derechos de los pueblos indígenas — consulta — Decreto Supremo $\mathrm{N}^{\circ} 124-$ Convenio OIT No 169 - Chile.

PARAULES CLAU: drets dels pobles indígenes - consulta — Decret Suprem $\mathrm{N}^{\circ} 124$ - Conveni OIT n. 169 - Xile.

KEYWORDS: rights of indigenous peoples — consult — Supreme Decree No. 124 ILO Convention n. 169 - Chile

Sumario: I. Introducción. II. Aspectos ambientales del derecho de consulta de los pueblos indígenas del Convenio $\mathrm{N}^{\circ}$ 169. 1. La consulta como herramienta para la protección de la tierra, el territorio y los recursos naturales. 2. Características del derecho de consulta del Convenio $\mathrm{N}^{\circ} 169$ de la OIT. 3. Relevancia de la protección del medio ambiente para los pueblos indígenas. III. La implementación del derecho de consulta del Convenio $N^{\circ} 169$ en Chile. 1. Carácter jurídico del Convenio $\mathrm{N}^{\circ}$ 169. 2. Constitucionalidad de las disposiciones sobre la consulta. 3. La nueva institucionalidad ambiental y la implementación de la consulta. IV. Análisis crítico del Decreto Supremo $\mathrm{N}^{\circ} 124$. 1. Nociones preliminares. 2. Críticas al Decreto Supremo $\mathrm{N}^{\circ}$ 124. 2.1. Cuestionamientos de forma. A. Decreto $\mathrm{N}^{\circ} 124$, dictado sin procedimiento de consulta previa. B. Críticas a la oportunidad y celeridad del procedimiento de aprobación. C. Críticas al pretendido carácter provisional. 2.2. Cuestionamientos de fondo. A. Equiparación de estándares de consulta. B. Limitación de la aplicación y obligatoriedad de la consulta. B.1. Según el órgano del cual emana el acto o medida. B.2. Según la materia: caso de los proyectos de inversión. B.3. Según el tipo de acto o medida administrativa de que se trate. C. Limitación de la oportunidad y plazo para realizar la consulta. 3. Fracaso de la implementación de la consulta del Decreto Supremo No 124. IV. Conclusiones. V. Bibliografía.

\section{INTRODUCCIÓN}

Con la entrada en vigencia en Chile el 15 de septiembre de 2009 del Convenio OIT $\mathrm{N}^{\circ}$ 169 de 1989 sobre Pueblos Indígenas y Tribales en Países Independientes ${ }^{1}$, instrumento que consagra importantes derechos colectivos de los pueblos indígenas, especialmente sobre sus tierras, territorios y recursos naturales, se dio un gran paso en el camino hacia

\footnotetext{
${ }^{1}$ En adelante, Convenio $\mathrm{N}^{\circ} 169$ o simplemente Convenio.
} 
el reconocimiento de los derechos de los pueblos originarios en un Estado que históricamente se ha mostrado refractario a impulsar el fortalecimiento de la institucionalidad indígena dentro del entramado jurídico interno.

Siendo Chile uno de los últimos países de la región en ratificar y aprobar este importante tratado multilateral ${ }^{2}$ — tras un dilatado proceso de casi dos décadas de discusiones y devaneos políticos ${ }^{3}$ - , las expectativas creadas en grandes sectores de la sociedad civil, así como en los representantes de los pueblos originarios, de ver significativos cambios en la condición de subordinación política, explotación económica y subvaloración cultural a que han estado sujetos los pueblos indígenas históricamente se han visto frustradas por una deficiente implementación del Convenio en el derecho interno.

Particularmente evidente ha sido la reticencia, por parte del Estado, de implementar adecuadamente aquellos derechos colectivos que el Convenio $\mathrm{N}^{\circ} 169-\mathrm{y}$ la reciente Declaración de Derechos de los Pueblos Indígenas de 2007- reconoce a estos pueblos sobre la tierra y los recursos naturales dentro de sus territorios, en especial el derecho a la consulta de buena fe, que constituye la base angular del sistema ${ }^{4}$.

2 Para ver el estado de ratificaciones, consúltese en el sitio oficial de la OIT: 〈http://www.ilo.org/ilolex/cgi-lex/ratifcs.pl?C169〉. Última visita, lunes 3 de octubre de 2011.

${ }^{3}$ Chile fue uno de los 49 Estados que se abstuvo de aprobar el Convenio el 27 de junio de 1989, durante el desarrollo de la Conferencia General de la Organización Internacional del Trabajo que creó este tratado. En diciembre de 1990 comenzó el tortuoso camino hacia su aprobación, con el primer trámite constitucional ante la Cámara de Diputados, que se inició con el Mensaje del Ejecutivo que contenía el "Proyecto de acuerdo relativo al Convenio No 169 sobre pueblos indígenas, adoptado por la Organización Internacional del Trabajo, el 27 de junio de 1989", contenido en el Boletín núm. 233-10, de 21 de diciembre de 1990, y el posterior "Informe de la Comisión de Derechos Humanos, Nacionalidad y Ciudadanía, recaído en el Proyecto de Acuerdo que aprueba el Convenio No 169 sobre Pueblos Indígenas y Tribales en Países Independientes", contenido en el Boletín núm. 233-10 (I), de 12 de marzo de 1991. Después de reiterados llamados del sistema de Naciones Unidas por la falta de ratificación del tratado, Chile dio paso al segundo trámite constitucional ante el Senado el 19 de julio de 2000, para recientemente darlo por concluido con el oficio para control de constitucionalidad ante el Tribunal Constitucional con fecha 5 de marzo de 2008. El instrumento de ratificación de dicho Convenio se depositó con fecha 15 de septiembre de 2008 ante el director general de la Organización Internacional del Trabajo y de conformidad con el artículo 38, párrafo 3, del Convenio $\mathrm{N}^{\mathrm{o}} 169$, entró en vigencia para Chile el 15 de septiembre de 2009. Para un análisis detallado de la historia de aprobación del Convenio $\mathrm{N}^{\circ} 169$, vid. Biblioteca del Congreso Nacional de Chile, Historia de la Ley Decreto $N^{\circ}$ 236, Ministerio Relaciones Exteriores, Promulga el Convenio No 169 sobre Pueblos Indígenas y Tribales en Países Independientes de la Organización Internacional del Trabajo. Recuperado el 11 de agosto de 2011 de: 〈http://www.bcn.cl/obtienearchivo?id=recursoslegales/10221.3/538/3/hdl-236.pdf».

4 Así lo ha interpretado la Comisión de Expertos en Aplicación de Convenios y Recomendaciones (CEACR) al señalar que "la Comisión toma nota de que el establecimiento de mecanismos apropiados y eficaces para la consulta y participación de los pueblos indígenas y tribales en relación con las cuestiones que les conciernen es la piedra angular del Convenio, aunque sigue siendo uno de los principales desafíos que plantea la aplicación del Convenio en una serie de países”. Comisión de Expertos en Aplicación de 
La toma de decisiones en materia ambiental por parte de las autoridades legislativas y administrativas que afecte a los intereses de los pueblos originarios e incida sobre el aprovechamiento económico de recursos y territorios de comunidades indígenas debe adecuarse a las nuevas obligaciones contraídas por el Estado chileno tras la entrada en vigencia del Convenio, para lo cual se ha tornado imprescindible la necesidad de adaptar tanto la institucionalidad indígena vigente como la normativa ambiental aplicable. Sin embargo, desde la firma del Convenio en 2008 y desde su entrada en vigencia en septiembre de 2009 hasta hoy poco se ha hecho al respecto. Peor aún, las medidas que se han adoptado para implementar estos derechos, más que un avance, se han convertido en verdaderos escollos que dificultan su ejercicio.

A lo largo de la presente nota analizaremos brevemente cómo se han implementado los aspectos ambientales del Convenio 169, en especial aquellos relacionados con el derecho de consulta de los pueblos indígenas. El análisis se centrará en el estudio del Decreto Supremo 124/2009, que crea el Reglamento sobre consulta y participación de pueblos indígenas, norma llamada a implementar en el ordenamiento jurídico chileno el artículo 34 sobre participación indígena de la Ley $\mathrm{N}^{\circ} 19.253$, pero que en la práctica se ha extendido a reglamentar el derecho a la consulta de buena fe contemplada en el Convenio 169 de la OIT, lo que ha sido objeto de una fuerte controversia por parte de la doctrina especializada.

\section{ASPECTOS AMBIENTALES DEL DERECHO DE CONSULTA DE LOS PUEBLOS INDÍGENAS DEL CONVENIO No 169}

\section{La consulta como herramienta para la protección de la tierra, el territorio y los recursos naturales}

El Convenio $\mathrm{N}^{\circ} 169$ de la OIT, principal instrumento jurídico de carácter vinculante que consagra derechos fundamentales de los pueblos indígenas ${ }^{5}$, establece en sus artículos 6

Convenios y Recomendaciones. (2009), pp. 731. "Informe de la Comisión de Expertos en Aplicación de Convenios y Recomendaciones", CEACR 2009/98a reunión. Recuperado el 2 de septiembre de 2011 de: 〈http://www.ilo.org/wcmsp5/groups/public/---ed_norm/--relconf/documents/meetingdocument/wcms_103488.pdf).

${ }^{5}$ El Convenio 169 de la OIT de 1989 significa un cambio de paradigma absoluto como instrumento internacional de derechos humanos. Deja atrás al Convenio 107 de la OIT, que había sido concebido en 1959 aún bajo la égida del asimilacionismo indígena y la óptica de supremacía cultural que impregna a la DUDH, y abandona de una buena vez la falacia supremacista de la individualidad necesaria y exclusiva de los derechos humanos aplicables con indiferencia del contexto en que se invoquen. Reconoce una serie 
y 7 disposiciones primordiales que definen la aplicación del Convenio en su conjunto y sientan las bases para la protección de los derechos colectivos de los pueblos indígenas reconocidos por el derecho internacional, en especial aquellos derechos que tienen relación con la tutela de los recursos naturales y el territorio.

El artículo 6 señala que, al aplicar el Convenio, los Gobiernos están obligados a realizar una consulta previa con los pueblos indígenas en aquellos casos que se prevean medidas legislativas o administrativas susceptibles de afectarles directamente. Además, el artículo 15 del Convenio agrega la obligación de consulta para conceder la autorización de cualquier programa de prospección o explotación de los recursos existentes en tierras indígenas o que afecte a sus intereses ${ }^{6}$.

El artículo 7, por su parte, dispone que los pueblos interesados tienen el derecho a decidir sus propias prioridades respecto al proceso de desarrollo y a controlar, en la medida de lo posible, su propio desarrollo económico, social y cultural. Según esta disposición, debe contemplarse, además, la participación de los pueblos en la formulación, ejecución y evaluación de los planes y programas de desarrollo que les afecten directamente. Asimismo, la norma señala que los Gobiernos deberán llevar a cabo, cada vez que sea apropiado y en cooperación con los pueblos indígenas, evaluaciones sobre los impactos que los programas y planes de desarrollo puedan ocasionar a nivel social, espiritual, cultural y medioambiental ${ }^{7}$.

Ambas disposiciones, tanto la consulta del artículo 6 como la participación del artículo 7, se encuentran íntimamente relacionadas, especialmente en materia ambiental. En este sentido la Comisión de Expertos en Aplicación de Convenios y Recomendaciones de la OIT (CEACR) ha declarado al respecto que "[1]a consulta, en el caso de recursos naturales y proyectos de desarrollo, es un requisito del Convenio que debe integrarse en un proceso participativo más amplio previsto en el artículo 7 del Convenio" ${ }^{8}$. De esta

de derechos individuales de las personas indígenas, pero asimismo consagra derechos colectivos y reconoce a las poblaciones originarias como pueblos con identidad propia y derecho a la propia determinación política, económica, social y cultural. Este proceso se ve robustecido tras la adopción en Naciones Unidas de la Declaración sobre los Derechos de los Pueblos Indígenas de 2007, que fortalece el derecho individual y colectivo a la autodeterminación y avanza aún más en la protección de los derechos colectivos de los pueblos indígenas.

${ }^{6}$ Vid. artículos 6 y 15 del Convenio OIT N ${ }^{\circ} 169$.

${ }^{7}$ Vid. artículo 7 del Convenio OIT $\mathrm{N}^{\circ} 169$.

${ }^{8}$ Comisión de Expertos en Aplicación de Convenios y Recomendaciones (2009), “Informe...”, cit., pp. 737. 
manera, el deber de los Estados de celebrar consultas de buena fe en aquellos procesos de toma de decisiones legislativas y administrativas que afecten a los pueblos indígenas se contempla vinculado de manera indisoluble a la participación. ${ }^{9}$

Conforme a estas disposiciones, el derecho de participación y consulta permite a las personas y los pueblos indígenas actuar como sujetos de derecho capaces de controlar sus propias instituciones sociales, políticas y culturales y de determinar el modelo de desarrollo que estimen adecuado; de esta forma se acaba con los modelos tutelares y paternalistas que por siglos regularon el estatuto jurídico del indígena ${ }^{10}$, bajo el modelo de Estado-nación imperante en Latinoamérica ${ }^{11}$.

De esta manera, la consulta previa se ha convertido en la herramienta más efectiva para tutelar los territorios y los recursos naturales de los pueblos indígenas, constituyéndose en el pilar a través del cual es posible comenzar a construir una sociedad multicultural,

\footnotetext{
${ }^{9}$ La dictación de la Declaración de las Naciones Unidas sobre los Derechos de los Pueblos Indígenas de 13 de diciembre de 2007 ha fortalecido este nexo, al disponer en su artículo 32 lo siguiente: "1. Los pueblos indígenas tienen derecho a determinar y elaborar las prioridades y estrategias para el desarrollo o la utilización de sus tierras o territorios y otros recursos. 2. Los Estados celebrarán consultas y cooperarán de buena fe con los pueblos indígenas interesados por conducto de sus propias instituciones representativas a fin de obtener su consentimiento libre e informado antes de aprobar cualquier proyecto que afecte a sus tierras o territorios y otros recursos, particularmente en relación con el desarrollo, la utilización o la explotación de recursos minerales, hídricos o de otro tipo. 3. Los Estados establecerán mecanismos eficaces para la reparación justa y equitativa por esas actividades, y se adoptarán medidas adecuadas para mitigar las consecuencias nocivas de orden ambiental, económico, social, cultural o espiritual".

${ }^{10}$ Para un análisis sobre el estatuto jurídico de los pueblos indígenas, vid. ANAYA S. J., Los Pueblos indígenas en el derecho internacional, Trotta, Madrid, 2004, capítulo 1, pp. 38 y ss.; RODRÍGUEZPIÑERO ROYO, L., "La OIT y los pueblos indígenas en el derecho internacional: del colonialismo al multiculturalismo", Aparicio Wilhelmi, M. (coord.), Caminos hacia el reconocimiento: pueblos indigenas, derechos y pluralismo / Camins cap al reconeixement: pobles indigenes, drets i pluralisme, Servei de Publicacions de la Universitat de Girona, Girona, 2005, pp. 102 y ss.; STAVENHAGEN, R., "Derecho Internacional y derechos indígenas", en Krotz, E., Antropología Jurídica: Perspectivas socioculturales en el Estudio del Derecho, Antropos-UAM, Barcelona, 2002, pp. 171 y ss., y KÖNIG, H., “¿Bárbaro o símbolo de la libertad? ¿Menor de edad o ciudadano? Imagen del indio y política indigenista en Hispanoamérica", König, Hans-Joachim (Ed.), El indio como sujeto y objeto de la historia latinoamericana. Pasado y presente, Vervuert Verlag, Iberoamericana, Madrid, 1998, pp. 15 y ss. Para un estudio de las etapas de las políticas asimilacionistas e indigenistas llevadas a cabo en Latinoamérica, vid. YRIGOYEN FAJARDO, R., "Hitos del Reconocimiento del pluralismo jurídico y el derecho indígena en las políticas indigenistas y el constitucionalismo andino", Berraondo, M. (coord.), Pueblos Indígenas y derechos humanos, Universidad de Deusto, Bilbao, 2006, pp. 537 y ss.

${ }^{11}$ La idea de Estado-nación, sobre todo en el contexto latinoamericano, no surge como continuador de formas de organización políticas anteriores, sino como sustitución o reemplazo que viene a destruir las organizaciones políticas de viejo cuño colonial en aras de construir un nuevo proyecto nacional. Para ello las élites criollas se inspiraron en una serie de nuevas ideas libertarias surgidas en el seno europeo y en el ejemplo independentista norteamericano: los ideales de la Ilustración, el aporte de Rousseau y de los enciclopedistas, y los valores de la independencia norteamericana y de la Revolución Francesa. En tal sentido, vid: APARICIO WILHELMI, M., Los Pueblos indígenas y el Estado: el reconocimiento constitucional de los derechos indígenas en América Latina, Cedecs, Barcelona, 2002, pp. 27 y ss., y DÍAZ-POLANCO, H., Autonomía regional. La autodeterminación de los pueblos indios, Siglo XXI editores, segunda edición aumentada, México, 1996, pp. 22 y ss.
} 
pluralista, democrática y plenamente participativa, y posibilitando, además, una adecuada protección del medio ambiente.

\section{Características del derecho de consulta del Convenio $\mathrm{N}^{\circ} 169$ de la OIT}

Conforme a lo que establece el artículo 6 del Convenio, la consulta debe efectuarse a los pueblos interesados mediante un procedimiento adecuado, a través de sus instituciones representativas, cada vez que se prevean medidas legislativas o administrativas susceptibles de afectarles directamente. Este proceso debe ser de buena fe y estar adecuado a las circunstancias, con la finalidad de llegar a un acuerdo o lograr el consentimiento acerca de las medidas propuestas ${ }^{12}$.

Si bien de la lectura de las disposiciones del Convenio pueden colegirse los caracteres básicos de la consulta, el relator especial de Naciones Unidas sobre los derechos de los pueblos indígenas, James Anaya, ha debido en repetidas oportunidades interceder para aclarar el sentido de los principios internacionales que informan la consulta y facilitar su aplicación ${ }^{13}$. Estos principios o criterios mínimos que son los requisitos esenciales de una consulta válida se han ido formando mediante la implementación de distintos mecanismos periódicos o contenciosos de supervisión de diversos órganos internacionales de derechos humanos, los órganos de control normativo de la OIT y distintas instancias de reclamación internacionales, $\mathrm{y}$ han sido recogidos progresivamente en la jurisprudencia sobre los pueblos indígenas.

Es así como, en relación con la implementación de la consulta en Chile, el relator especial, en su informe "Los principios internacionales aplicables a la consulta en relación con la reforma constitucional en materia de derechos de los pueblos indígenas en Chile", de 24 de abril de $2009^{14}$, ha sistematizado estos caracteres, señalando los

\footnotetext{
${ }^{12}$ Vid. artículo 6, Convenio OIT N 169.

13 A modo de ejemplo, vid. relator especial de Naciones Unidas sobre la situación de los derechos humanos y las libertades fundamentales de los indígenas, ANAYA, J. (2009, 15 de julio), "Informe del relator especial sobre la situación de los derechos humanos y las libertades fundamentales de los indígenas", presentado al Consejo de Derechos Humanos, $12^{\circ}$ período de sesiones, A/HRC/12/34, pp. 13 y ss. Recuperado el 8 de septiembre de 2011 de: 〈http://unsr.jamesanaya.org/esp/docs/annual/2009_hrc_annual_report_sp.pdf〉.

14 Relator especial de Naciones Unidas sobre la situación de los derechos humanos y las libertades fundamentales de los indígenas, ANAYA, J. (2009, 24 de abril), "Principios internacionales aplicables a la consulta en relación con la reforma constitucional en materia de derechos de los pueblos indígenas en Chile". Recuperado el 8 de septiembre de 2011 de:

〈http://unsr.jamesanaya.org/esp/docs/special/2009_special_chile_informeconsulta_abril09_sp.pdf〉.
} 
requisitos fundamentales para asegurar su implementación conforme a las normas de derecho internacional de los pueblos indígenas.

Según Anaya, los principios de esta consulta son, a grandes rasgos, los siguientes: 1) debe realizarse con carácter previo, antes de que las medidas administrativas o legislativas se adopten, a fin de obtener el consentimiento libre e informado; 2) no se agota con la mera información, por cuanto lo que persigue es promover un diálogo efectivo con las instituciones representativas de los pueblos indígenas; 3) debe ser un proceso de buena fe, esto es, dentro de un procedimiento que genere confianza entre las partes y signifique un verdadero proceso de participación; 4) debe ser adecuada y a través de las instituciones representativas indígenas, por lo que debe efectuarse tomando en cuenta las costumbres y los métodos tradicionales de los pueblos originarios, buscando la amplia participación de las comunidades y con plazos que respeten sus procesos de toma de decisión, y 5) debe tratarse de un proceso sistemático y transparente, con procedimientos más o menos formalizados que sean a su vez resultado de un proceso consensuado con la participación activa de los pueblos indígenas ${ }^{15}$.

Por las características mismas de la consulta, al estar este mecanismo de participación fuertemente imbricado con el derecho a la autonomía de los pueblos indígenas y, por ende, con la capacidad inherente de determinar libremente el modelo de desarrollo económico y la administración de los recursos naturales que se encuentran en sus territorios, es vista con fuerte recelo por parte de algunos Gobiernos y grupos de poder, que niegan cualquier efecto vinculante a los procesos de consultas y consideran sus resultados como meras recomendaciones o simples antecedentes a tener en cuenta en la concreción de proyectos de inversión en territorios indígenas.

Sin embargo, la posibilidad de que a través de un proceso de consulta puedan entablarse espacios de diálogo entre Gobiernos, agentes económicos, sociedad civil y pueblos indígenas redunda en beneficio de todos por cuanto, además de tratarse de una manifestación del principio democrático, permite ampliar el abanico de herramientas para alcanzar una efectiva tutela del medio ambiente en un modelo de sociedad inserta en un contexto de desarrollo sostenible.

\footnotetext{
${ }^{15}$ Para un análisis en profundidad de estos requisitos, vid. relator especial de Naciones Unidas, ANAYA, J., "Principios Internacionales...", cit., pp. 4 y ss.
} 


\section{Relevancia de la protección del medio ambiente para los pueblos indígenas}

El derecho a la consulta previa de buena fe contemplado en el Convenio 169 se ha convertido en la principal herramienta esgrimida por las comunidades y asociaciones indígenas para el control de las decisiones con relevancia ambiental que recaigan sobre territorios y recursos naturales de los pueblos indígenas. Es un derecho que entronca con las raíces de la identidad de los pueblos originarios y posibilita la propia persistencia de estas comunidades por cuanto garantiza el respeto del entorno en el cual se desarrollan y viven.

Esta relación ha sido reconocida no tan solo en el Convenio $\mathrm{N}^{\circ} 169^{16}$, sino que la Comisión Interamericana de Derechos Humanos (CIDH) señala que tanto el artículo 21 de la Convención Americana como el artículo XXIII de la Declaración Americana, que resguardan el derecho a la propiedad, también protegen esta vinculación estrecha que guardan los pueblos originarios con las tierras, así como con los recursos naturales de los territorios ancestrales ${ }^{17}$, vínculo que se ha visto resguardado por la CIDH y la Corte Interamericana en fallos tan significativos como el caso de la Comunidad Mayagna (Sumo) Awas Tingni contra Nicaragua, de 31 de agosto de 2001, o el caso del Pueblo Saramaka contra Surinam, de 28 de noviembre de 2007, entre otros ${ }^{18}$.

Ello se debe a que la importancia del medio ambiente para los pueblos indígenas es superlativa, no como un bien económico en sí, sino como fundamento de existencia del $\operatorname{ser}^{19}$. Como sostiene Mikel Berraondo, el medio ambiente supone la causa principal de

\footnotetext{
${ }^{16}$ Artículo 13.1: “Al aplicar las disposiciones de esta parte del Convenio, los gobiernos deberán respetar la importancia especial que para las culturas y valores espirituales de los pueblos interesados reviste su relación con las tierras o territorios, o con ambos, según los casos, que ocupan o utilizan de alguna otra manera, y en particular los aspectos colectivos de esa relación”. Convenio OIT N 169.

17 Vid. Organización de Estados Americanos OEA, Comisión Interamericana de Derechos Humanos CIDH (2009, 30 de diciembre), "Derechos de los pueblos indígenas y tribales sobre sus tierras ancestrales y recursos naturales. Normas y jurisprudencia del Sistema Interamericano de Derechos Humanos" OEA/Ser.L/V/II. Doc. 56/09, pp. 21 y ss. Recuperado el 11 de agosto de 2011 de: 〈http://cidh.org/countryrep/TierrasIndigenas2009/Tierras-Ancestrales.ESP.pdf〉.

18 Vid. Organización de Estados Americanos OEA, Comisión Interamericana de Derechos Humanos CIDH, "Derechos...", cit., pp. 21 y ss.

${ }^{19}$ Al respecto, la célebre sentencia de la Corte Interamericana de Derechos Humanos en el caso de la Comunidad Mayagna (Sumo) Awas Tingni contra Nicaragua enfatiza la importancia de la estrecha relación de los pueblos indígenas con el entorno, cuando señala en su párrafo 149 ciertas precisiones sobre el concepto de propiedad indígena: "Entre los indígenas existe una tradición comunitaria sobre una forma comunal de la propiedad colectiva de la tierra, en el sentido de que la pertenencia de ésta no se centra en un individuo sino en el grupo y su comunidad. Los indígenas por el hecho de su propia existencia tienen derecho a vivir libremente en sus propios territorios; la estrecha relación que los indígenas mantienen con la tierra debe ser reconocida y comprendida como la base fundamental de sus culturas, su vida espiritual, su integridad y su supervivencia económica. Para las comunidades indígenas
} 
la propia existencia de los pueblos indígenas, ya que es el "punto donde confluye su existencia con sus creencias, con sus prácticas culturales y con sus recursos económicos. [...] Para ellos la tierra está dotada de un significado sagrado, está integrada con las relaciones sociales y es fundamental para poder definir la existencia e identidad de un pueblo" ${ }^{20}$.

En atención a ello, el derecho al medio ambiente como derecho humano de tercera generación ${ }^{21}$ presenta ciertas singularidades cuando se trata de pueblos indígenas. En primer lugar, siguiendo al autor mencionado, para los pueblos indígenas es un derecho colectivo más que un derecho individual, ya que se contempla como un derecho de disfrute de la comunidad en su conjunto. Es, además, un derecho basado en la solidaridad, pero no entendida exclusivamente entre las personas que disfrutan y se benefician de ese medio ambiente, sino también y principalmente con las generaciones futuras. Además, es un derecho-condición, ya que el medio ambiente adecuado supone una condición para que los pueblos indígenas y las personas indígenas puedan sobrevivir y ejercitar el resto de derechos humanos ${ }^{22}$. Por estas razones se constituye en el derecho principal y esencial para el desarrollo de las formas de vida tradicionales, $y$, en definitiva, para la existencia y el desarrollo de los pueblos indígenas en general.

la relación con la tierra no es meramente una cuestión de posesión y producción sino un elemento material y espiritual del que deben gozar plenamente, inclusive para preservar su legado cultural y transmitirlo a las generaciones futuras". Corte Interamericana de Derechos Humanos, caso de la Comunidad Mayagna (Sumo) Awas Tingni contra Nicaragua, Sentencia de 31 de agosto de 2001 (Fondo, Reparaciones y Costas), párrafo 149, p. 78. Recuperado el 12 de agosto de 2011 de: 〈http://www.corteidh.or.cr/docs/casos/articulos/Seriec_79_esp.pdf〉.

${ }^{20}$ BERRAONDO LÓPEZ, M., "Derecho humano al medio ambiente y pueblos indígenas. Dos derechos con un mismo fin”, Mariño Menéndez, F., Oliva Martínez, D. (eds.), Avances en la protección de los derechos de los pueblos indígenas, Dykinson, Madrid, 2004. pp.73 y 74.

${ }^{21}$ El carácter de estos derechos de tercera generación está sujeto a controversias, ya que se trata de derechos de reciente aparición, y como diría Martínez de Pisón, aún son objeto de estudio y atención pues sus perfiles no están muy claros y plantean dudas sobre su titularidad y sobre otros aspectos de su naturaleza - quién puede requerirlos, quién es el obligado, cuáles son, su objeto, qué sanciones pueden imponerse, cómo, a quién-, pero al parecer hay consenso de que surgen como expresión de la solidaridad entre seres humanos. Son derechos que "vienen a reflejar las nuevas realidades que surgen en el planeta y las profundas transformaciones económicas, políticas, sociales y culturales que se están produciendo por el impacto de las innovaciones tecnológicas en la vida de los hombres". Vid. MARTÍNEZ DE PISÓN, J., Políticas de Bienestar. Un estudio sobre los derechos sociales, Tecnos, Madrid, 1998, pp. 72. Sin embargo, se suele señalar que la tercera generación de derechos fundamentales o derechos de la solidaridad se articula sobre la base del derecho al medio ambiente adecuado. Ruiz-Rico Ruiz menciona al respecto que "[e]l medio ambiente constituye el punto central de referencia sobre el que gravita la última generación de derechos humanos, que tiene además en el principio de la solidaridad su común denominador". RUIZ-RICO RUIZ, Gerardo, El derecho constitucional al medio ambiente, Tirant lo Blanch, Valencia, 2000, pp. 69.

${ }^{22}$ Cfr. BERRAONDO LÓPEZ, “Derecho humano...”, cit., pp. 75. 


\section{LA IMPLEMENTACIÓN DEL DERECHO DE CONSULTA DEL CONVENIO N 169 EN CHILE}

\section{Carácter jurídico del Convenio $\mathrm{N}^{\circ} 169$}

El Convenio 169 es un instrumento de derecho internacional que tiene el carácter jurídico de un tratado de derechos humanos, tanto por su contenido y su objeto como por su fundamento ${ }^{23}$. Así lo ha entendido el legislador al incorporarlo al derecho interno chileno, lo cual ha quedado de manifiesto en la tramitación misma del proyecto de acuerdo que aprobó el Convenio $\mathrm{N}^{\circ} 169$ de la OIT cuando la propia Comisión de Derechos Humanos, Nacionalidad y Ciudadanía en su primer informe de tramitación señaló que el ámbito de competencia fijado por la Cámara a dicha Comisión tenía por objeto "informar los proyectos de ley y los tratados internacionales que contemplen normas sobre derechos humanos, nacionalidad y ciudadanía", a la vez que "defender y promover los derechos fundamentales del hombre, consagrados en la Constitución Política y en los tratados internacionales" ${ }^{\prime 24}$.

El artículo 5, inciso 2, de la Constitución chilena, luego de la reforma introducida en el texto constitucional en $1989^{25}$, exige un tratamiento especial respecto a la recepción de los tratados internacionales recaídos en materia de derechos fundamentales, por cuanto esta disposición reconoce la inmediata aplicación del orden internacional por los

\footnotetext{
${ }^{23}$ Conforme a lo que se establece en el propio preámbulo del Convenio $\mathrm{N}^{\circ} 169$, sus preceptos se basan en otros instrumentos internacionales de derechos humanos, entre los que se puede mencionar la Declaración Universal de Derechos Humanos, el Pacto Internacional de Derechos Económicos, Sociales y Culturales y el Pacto Internacional de Derechos Civiles y Políticos. Vid. preámbulo Convenio OIT N ${ }^{\circ} 169$. El carácter del Convenio como tratado sobre derechos humanos es resaltado por el propio relator especial James Anaya, vid. relator especial ANAYA, J., "Informe del Relator Especial sobre la situación...", cit., pp. 13 y ss.

${ }^{24}$ Comisión de Derechos Humanos, Nacionalidad y Ciudadanía (1991, 12 de marzo). Informe de la Comisión de Derechos Humanos, Nacionalidad y Ciudadanía, recaído en el Proyecto de Acuerdo que aprueba el Convenio $\mathrm{N}^{\circ} 169$ sobre Pueblos Indígenas y Tribales en Países Independientes, Boletín núm. 233-10 (I), en Biblioteca del Congreso Nacional de Chile, Historia de la Ley Decreto $\mathrm{N}^{\circ}$ 236, Ministerio Relaciones Exteriores, Promulga el Convenio $\mathrm{N}^{\circ} 169$ sobre Pueblos Indígenas y Tribales en Países Independientes de la Organización Internacional del Trabajo, p. 8. Recuperado el 11 de agosto de 2011 de: 〈http://www.bcn.cl/obtienearchivo?id=recursoslegales/10221.3/538/3/hdl-236.pdf〉.

${ }^{25}$ La reforma constitucional de 1989 de la Constitución Política de 1980 -texto constitucional creado bajo la dictadura de A. Pinochet - fue el resultado de un acuerdo entre el Gobierno militar, la Concertación de Partidos por la Democracia (centroizquierda) y el Partido Renovación Nacional (derecha) para introducir reformas con el fin de que hubiera gobernabilidad democrática durante el proceso de transición tras la derrota de Pinochet en el plebiscito de 1988. Esta modificación fue aprobada posteriormente por la Junta Militar de Gobierno de la época y sometida a plebiscito en conformidad con la normativa transitoria fijada por el propio texto constitucional.
} 
órganos estatales en cuanto receptores de derechos esenciales consagrados en tratados internacionales sobre derechos humanos ${ }^{26}$.

En función de esta importante norma constitucional, la doctrina sostiene de forma mayoritaria que los derechos esenciales asegurados en tratados internacionales que versen sobre derechos humanos constituyen un límite a la soberanía ${ }^{27}$ e implican una limitación constitucional al poder normativo del Congreso ${ }^{28}$ por cuanto, como sostienen Mario Verdugo, Emilio Pfeffer y Humberto Nogueira, sus disposiciones se incorporan al ordenamiento jurídico interno, formando parte de la Constitución material y adquiriendo plena vigencia, validez y eficiencia jurídicas, no pudiendo ningún órgano del Estado desconocer los derechos en él consagrados y cualquier reforma constitucional recaída sobre un tratado de derechos humanos solo puede modificar sus normas en la medida en que implique una mayor garantía y protección de estos derechos, no pudiendo desmejorar su situación jurídica. Más aún, los órganos del Estado están obligados a promover y respetar estos derechos por cuanto su vulneración constituiría una trasgresión tanto de la Constitución como del tratado internacional, acarreando las consecuencias que ello implica tanto en el ámbito interno como internacional ${ }^{29}$.

\footnotetext{
${ }^{26}$ El artículo 5, inciso $2^{\circ}$, de la Constitución chilena, reformado en 1989 , señala respecto de los tratados internacionales que versen sobre derechos humanos que "[e]1 ejercicio de la soberanía reconoce como limitación el respeto a los derechos esenciales que emanan de la naturaleza humana. Es deber de los órganos del Estado respetar y promover tales derechos, garantizados por esta Constitución, así como por los tratados internacionales ratificados por Chile y que se encuentren vigentes". Artículo 5, Constitución Política de la República de Chile de 1980.

${ }^{27}$ A modo de ejemplo, los célebres tratadistas Verdugo, M., Pfeffer, E. y Nogueira, H. señalan que en Chile los derechos humanos se consideran como límite a la soberanía estatal (artículo 5, inciso $2^{\circ}$ ), protegiendo nuestro ordenamiento jurídico los derechos que "garantizan la constitución y los tratados internacionales ratificados por Chile y que se encuentran vigentes". Vid. VERDUGO, M., PFEFFER, E. y NOGUEIRA, H., Derecho Constitucional, tomo I, $2^{\text {a }}$ edición, Editorial Jurídica de Chile, Santiago, 2005, p. 129.

${ }^{28}$ Vid. MONTT OYARZÚN, S., y MATTA AYLWIN, M., "Una visión panorámica al Convenio OIT 169 y su implementación en Chile", Estudios Públicos núm. 121, verano 2011, pp. 166 y ss.

${ }^{29}$ Verdugo, M., Pfeffer, E. y Nogueira, H. sostienen que la institucionalización de derechos humanos contenidos en tratados internacionales produce las siguientes consecuencias en el ordenamiento jurídico interno chileno: 1) Conforme a lo dispuesto en el artículo 5, inciso $2^{\circ}$, de la Constitución, los derechos asegurados en el tratado se incorporan al ordenamiento jurídico interno, formando parte de la Constitución material y adquiriendo plena vigencia, validez y eficiencia jurídicas, no pudiendo ningún órgano del Estado desconocerlos, estando obligado a promoverlos y respetarlos. 2) La vulneración de los derechos consagrados en el tratado constituye una trasgresión tanto de la Constitución como del tratado internacional, acarreando las consecuencias que ello implica tanto en el ámbito interno como internacional. 3) Incorporado el derecho a su protección por medio del tratado, este adquiere aplicación inmediata sin necesidad de reforma constitucional, ya que de lo contrario se estaría incumpliendo el deber y mandato imperativo y perentorio de respeto y promoción que la Constitución ordena a todos los órganos del Estado. 4) Una reforma constitucional recaída sobre un tratado de derechos humanos solo puede
} 
De esta manera, conforme a lo que la propia norma fundamental señala y así lo ha aceptado la jurisprudencia y la doctrina, en Chile se entiende que la carta fundamental reconoce un rango de primacía a disposiciones internacionales sobre derechos humanos en relación con el ordenamiento interno por encima del que puedan tener otras disposiciones relativas a tratados de otra naturaleza ${ }^{30}$.

El Convenio $\mathrm{N}^{\mathrm{o}} 169$ posee carácter vinculante respecto de aquellos Estados que han firmado y ratificado el instrumento y respecto de los cuales se encuentre vigente en su derecho interno, como es el caso de Chile. En virtud de lo señalado sostenemos que las disposiciones del Convenio constituyen un límite a la soberanía del Estado por cuanto este ha sido incorporado al derecho interno chileno, contemplándose su carácter de instrumento internacional sobre derechos humanos, con todas las consecuencias que ello implica $^{31}$.

\section{Constitucionalidad de las disposiciones sobre la consulta}

Entendiendo el Convenio $\mathrm{N}^{\circ} 169$ como un instrumento internacional sobre derechos humanos con primacía respecto al ordenamiento interno, que a su vez constituye un límite al ejercicio de la soberanía del Estado, se ha sostenido que todas las normas del Convenio son autoejecutables, aunque ello no implique necesariamente que los derechos humanos reconocidos sean todos plenamente justiciables ${ }^{32}$.

modificar sus normas en la medida en que implique una mayor garantía y protección de estos derechos, no pudiendo desmejorar su situación jurídica. Cfr. VERDUGO, M., PFEFFER, E. y NOGUEIRA, H., "Derecho Constitucional...", cit., p. 126 y ss.

${ }^{30}$ Vid. GAETE GONZÁLEZ, E., "Derecho Internacional y Derechos de los Estados: incorporación de los derechos humanos", Revista Chilena de Derecho, vol. 23, núms. 2 y 3, tomo I, 1996, pp. 268 y ss.

${ }^{31}$ Para un análisis exhaustivo de la naturaleza del Convenio 169 en el ordenamiento jurídico chileno, vid. MONTT OYARZÚN, S., y MATTA AYLWIN, M., "Una visión panorámica...”, cit., pp. 152 y ss.

${ }^{32}$ Al respecto Montt Oyarzún, S., y Matta Aylwin, M., han señalado que el mandato contenido en el artículo 5, inciso $2^{\circ}$, de la Constitución dirigido a los órganos estatales implica una limitación constitucional al poder normativo del Congreso, no pudiéndose por tanto derogar o disponer la inaplicación interna de un tratado de derechos humanos, lo que supone en la práctica que estos quedan en una posición superior a las leyes ordinarias, derogando el derecho interno anterior y no pudiéndose derogar por la actividad normativa posterior del Congreso, lo que acarrea como consecuencia que "[c]omo corolario de lo anterior, la correcta interpretación del artículo 5' de la Constitución debe ser que los tratados de derechos humanos son siempre autoejecutables", aunque "la justiciabilidad de sus derechos deba ser evaluada conforme a las mismas reglas que aplican a los demás derechos fundamentales reconocidos en el orden interno". MONTT OYARZÚN, S., y MATTA AYLWIN, M., "Una visión...", cit., p. 166 y 167. 
El Tribunal Constitucional chileno, si bien ha estimado que el Convenio $\mathrm{N}^{\mathrm{o}} 169$ no vulnera la Constitución ni en la forma ni en el fondo, ha efectuado una serie de precisiones interpretativas en cuanto a su aplicación que restan fuerza de forma considerable a una implementación efectiva de este.

En primer lugar, en Sentencia Rol No 309, del 4 de agosto de 2000, el TC establece que las disposiciones del Convenio son "programáticas", esto es, que no son normas autoejecutables y solo son aplicables si son compatibles con el sistema jurídico interno $^{33}$. De este modo se le niega fuerza normativa a este tratado internacional sobre derechos humanos, supeditando su cumplimiento a la voluntad del poder legislativo, lo cual es una abierta contradicción con el derecho de los tratados y con el cumplimiento de los instrumentos sobre derechos humanos.

Sorprendentemente, las únicas normas que este fallo considera que poseen carácter autoejecutable y plenamente justiciables son las normas sobre la consulta, ya que sostiene que están redactadas de forma imperativa y constituyen, además, preceptos que modifican normas propias de leyes orgánicas constitucionales y, por ende, como lo ha declarado reiteradamente el propio Tribunal, tienen el carácter de esta clase de leyes.

Debemos precisar que el Tribunal Constitucional tan solo ha manifestado esta autoejecutabilidad respecto de dos apartados específicos del Convenio: el artículo $6, \mathrm{n}^{\circ}$ 1, letra a), $\mathrm{y}^{\mathrm{o}} 2$, que trata propiamente sobre la consulta, y el $7, \mathrm{n}^{\mathrm{o}} 1$, oración segunda, que versa sobre la participación en la formulación, aplicación y evaluación de los planes y programas de desarrollo nacional y regional susceptibles de afectarles directamente. Sin embargo, pese a todas las trabas existentes, este reconocimiento de la autoejecutabilidad de las normas de la consulta ha significado un gran impulso para la implementación de este derecho, y en la práctica ha hecho exigible el respeto de los derechos sobre las tierras y los recursos naturales de los pueblos indígenas reconocidos en el Convenio, permitiendo su ejercicio ante tribunales y siendo acogido por la jurisprudencia.

\footnotetext{
${ }^{33}$ En este sentido se señala en el fallo que "[e]1 Convenio no ejecuta por sí mismo las medidas de que se trata, sino que invita al Estado parte a ponerlas en ejecución, debiendo adoptarse de acuerdo con el ordenamiento jurídico de cada Estado", y que "[1]a norma en análisis va a recibir aplicación sólo en cuanto sea compatible con el sistema jurídico propio". Con ello, según el fallo, se demuestra el carácter esencialmente programático de este tratado internacional, ejemplificado con la utilización de frases como “'deberán reconocerse', 'deberán tomarse medidas', 'deberá prestarse particular atención', 'los gobiernos deberán', 'deberán instituirse procedimientos adecuados en el marco del sistema jurídico nacional', lo que permite concluir que tales disposiciones responden al tipo de preceptos no ejecutables con el sólo mérito del tratado". Tribunal Constitucional, Sentencia Rol No 309, de 4 de agosto de 2000.
} 
Además, este fallo precisa el carácter especialísimo de la consulta a los pueblos indígenas del artículo 6, inciso primero, del Convenio, diferenciándola de cualquier otro proceso de consulta establecido en la legislación interna chilena, afirmando que esta "tiene una connotación jurídica especial" 34 , que es precisada por el $n^{\circ} 2$ del mismo artículo 6, que establece los caracteres esenciales de la consulta, ya analizados en el apartado anterior.

El Tribunal Constitucional volvió a pronunciarse sobre la consulta cuando la Cámara de Diputados envió en marzo de 2008 el "Proyecto de Acuerdo aprobatorio relativo al Convenio $N^{\circ} 169$ ”. En esta oportunidad, en Sentencia Rol 1050, de 3 de abril de 2008, interpreta nuevamente el alcance del Convenio, aunque esta vez limitando seriamente la aplicación de la consulta, al señalar que el deber de consulta es un mecanismo de participación que no tiene carácter vinculante; por ello "no importa una negociación obligatoria, sino que constituye una forma de recabar opinión, misma que no resultará vinculante, ni afectará las atribuciones privativas de las autoridades que la Constitución Política de la República establece" 35 .

Se concluye de esta manera que si bien el Tribunal Constitucional establece, por una parte, la autoejecutabilidad de la consulta, entendiéndose en consecuencia que estas normas de participación y consulta forman parte del ordenamiento interno chileno, por otra, interpreta de una manera sumamente restrictiva su obligatoriedad, contraviniendo las normas esenciales del Convenio sobre el carácter imperativo de la consulta previa de buena fe.

\section{La nueva institucionalidad ambiental y la implementación de la consulta}

Tras la entrada en vigencia del Convenio $\mathrm{N}^{\circ} 169$ en septiembre de 2009, se hizo necesario verificar cómo se debía implementar esta normativa en relación con la institucionalidad ambiental.

Teniendo en cuenta que la institucionalidad ambiental en Chile se encuentra en pleno proceso de reforma por cuanto la Ley $\mathrm{N}^{\mathrm{o}} 19.300$ de Bases Generales del Medio

\footnotetext{
34 Tribunal Constitucional, Sentencia Rol No 309, de 4 de agosto de 2000.

35 Sentencia Rol 1050, 03/04/2008. Control de constitucionalidad del proyecto de acuerdo aprobatorio relativo al Convenio $N^{o} 169$ sobre Pueblos Indígenas, adoptado por la Organización Internacional del Trabajo, de 27 de junio de 1989.
} 
Ambiente $^{36}$, pilar fundamental de la legislación ambiental, ha sido modificada recientemente por la Ley $\mathrm{N}^{\circ} 20.417^{37}$ —promulgada en enero de 2010, con posterioridad a la entrada en vigencia del Convenio $\mathrm{N}^{\circ} 169-$, nos enfrentamos a nuevos paradigmas que recién están iniciando sus ajustes.

\section{La Ley $N^{\circ} 20.417$ introdujo en el inciso $2^{\circ}$ del artículo 4 de la Ley de Bases Generales} de Medio Ambiente $\mathrm{N}^{\circ} 19.300$ una directriz normativa de carácter general dirigida a la actuación de los órganos competentes del Estado en materia ambiental cuando dicha actuación tenga incidencia sobre intereses de los pueblos originarios. En función de esta norma se establece una obligación para los órganos del Estado, en el ejercicio de sus competencias ambientales y en la aplicación de los instrumentos de gestión ambiental, de propender por la adecuada conservación y protección de los pueblos indígenas de conformidad con lo señalado en la ley y en los convenios internacionales ratificados por Chile y que se encuentren vigentes ${ }^{38}$, entre los cuales se halla el Convenio $\mathrm{N}^{\circ} 169$.

\footnotetext{
${ }^{36}$ Ley N ${ }^{\circ} 19.300$ de Bases Generales del Medio Ambiente (DO 09/03/1994).

${ }^{37}$ La Ley N ${ }^{\circ} 20.417$ crea el Ministerio, el Servicio de Evaluación Ambiental y la Superintendencia del Medio Ambiente (DO 26/01/2010). Esta norma, conocida como Ley de la Nueva Institucionalidad Ambiental, introduce amplias reformas en la Ley N ${ }^{\circ} 19.300$ de Bases Generales del Medio Ambiente, creando el nuevo Ministerio de Medio Ambiente, el Comité de Ministros, el Consejo de Ministros para la Sustentabilidad y el Servicio de Evaluación Ambiental. Además, introduce cambios para fomentar el procedimiento de evaluación ambiental en Gobiernos regionales y municipalidades, y crea un proceso facultativo de participación ciudadana frente a las declaraciones de impacto ambiental, así como procesos voluntarios de evaluación y certificación respecto de proyectos y actividades sujetos a declaración de impacto ambiental. Por otro lado, consagra el derecho de acceso a la información ambiental en poder de la Administración, creando un registro público y un sistema nacional para tales efectos. En materia de fiscalización, establece la Superintendencia del Medio Ambiente, órgano encargado de los procedimientos de fiscalización y sanción de las resoluciones de calificación ambiental, de las medidas de los planes de prevención y/o descontaminación ambiental, del contenido de las normas de calidad ambiental y de emisión, y de los planes de manejo, entre otras resoluciones con relevancia ambiental, bajo supervisión de la Contraloría General de la República, máximo ente fiscalizador de la actividad de la Administración. Por último, introduce una serie de modificaciones en normativas sectoriales con el objeto de conciliar las atribuciones y competencias del nuevo Ministerio de Medio Ambiente, como en la Ley General de Pesca y Acuicultura (texto refundido por el Decreto Supremo $N^{\circ} 430$, de 1992), la Ley $\mathrm{N}^{\circ}$ 17.288 de Monumentos Nacionales, el Decreto Ley del Ministerio de Tierras y Colonización $\mathrm{N}^{\circ} 1.939$, del año 1977, sobre Adquisición, Administración y Disposición de Bienes del Estado, la Ley Orgánica de Municipalidades (texto refundido por el Decreto con Fuerza de Ley $\mathrm{N}^{\circ} 1$, del año 2006), el Decreto con Fuerza de Ley $\mathrm{N}^{\circ}$ 294, del año 1960, del Ministerio de Hacienda, sobre Funciones y Estructura del Ministerio de Agricultura, el Código de Aguas y la Ley $N^{\circ} 18.902$, que crea la Superintendencia de Servicios Sanitarios.

38 "Artículo primero.- Introdúcense las siguientes modificaciones en la ley $\mathrm{N}^{\mathbf{0}} 19.300$, sobre Bases Generales del Medio Ambiente [... 2) En el artículo $4^{\circ}[\ldots]$ b) Agrégase el siguiente inciso segundo: Los órganos del Estado, en el ejercicio de sus competencias ambientales y en la aplicación de los instrumentos de gestión ambiental, deberán propender por la adecuada conservación, desarrollo y fortalecimiento de la identidad, idiomas, instituciones y tradiciones sociales y culturales de los pueblos, comunidades y personas indígenas, de conformidad a lo señalado en la ley y en los convenios internacionales ratificados por Chile y que se encuentren vigentes". Ley $\mathrm{N}^{\circ}$ 20.417, que crea el Ministerio, el Servicio de Evaluación Ambiental y la Superintendencia del Medio Ambiente (DO 26/01/2010).
} 
Sin embargo, la nueva reforma de la institucionalidad ambiental, que ha significado un notable avance en materia de fortalecimiento y ampliación de la participación ciudadana dentro del Sistema de Evaluación de Impacto Ambiental (SEIA), no ha introducido norma alguna para asegurar la participación y consulta de los pueblos indígenas en los procesos contemplados en su entramado jurídico. No ha efectuado reconocimientos diferenciados de procedimientos de consulta previa que presten atención a la especialidad y particularidad de los intereses de los pueblos indígenas, en especial a la delicada relación que existe entre territorio e identidad, salvo la precisión de carácter general ya mencionada y las normas sobre participación indígena contenidas en el proyecto de Nuevo Reglamento del SEIA, que aún no ha sido aprobado ${ }^{39}$.

El único esfuerzo legislativo que se ha efectuado hasta la fecha para la implementación de la consulta en Chile ha sido el Decreto Supremo $N^{\circ} 124$, norma que no satisface los estándares internacionales sobre derechos de los pueblos indígenas y que analizaremos a continuación.

\footnotetext{
${ }^{39}$ El proyecto de Nuevo Reglamento del SEIA ha considerado la incorporación de elementos propios de participación para los pueblos indígenas con el objeto de asegurar la pertinencia cultural de dicha participación. De esta manera, el artículo 83 del Reglamento se refiere a la participación indígena en la evaluación de impacto ambiental (EIA) y su artículo 84 se refiere a la participación indígena en las declaraciones de impacto ambiental (DIA): "Artículo 83.- Participación indígena: En el caso de proyectos o actividades que generan o presentan alguno de los efectos, características o circunstancias indicados en los 7, 8 y 10 de este Reglamento, en la medida que afecten a pueblos indígenas, se deberá desarrollar un proceso de participación que contemplará los mecanismos apropiados para que éstos puedan participar de manera informada, según las características socioculturales propias de cada pueblo. De igual manera, se deberán establecer los procedimientos que aseguren que estos pueblos estarán informados durante el proceso de evaluación de impacto ambiental sobre las aclaraciones, rectificaciones y/o ampliaciones de que hubiese sido objeto el Estudio de Impacto Ambiental, incluyendo la manera en que sus observaciones han sido abordadas en aquéllas.

Artículo 84.- Período de información y difusión a grupos humanos indígenas: Cuando el proyecto o actividad sometido a evaluación mediante una Declaración de Impacto Ambiental se emplace en tierras indígenas, áreas de desarrollo indígena o próximo a grupos humanos indígenas, el Director Regional o el Director Ejecutivo del Servicio, según corresponda, podrá realizar un período de información y difusión a dichos grupos, localizados en el área en que se desarrollará el proyecto o actividad, por un período no superior a 20 días, con el objeto de determinar la procedencia de la aplicación del artículo 46 del presente Reglamento en relación a la afectación de pueblos indígenas. En este caso se generará un acta de cada uno de los procesos de información y difusión en donde se recogerán las opiniones de los referidos grupos".
}

Además, se contempla la creación de una Guía de Apoyo para la Evaluación de Efectos Significativos sobre Pueblos Originarios en el SEIA, con el objetivo de fomentar y promover mejoras en la evaluación de impacto ambiental de los proyectos o las actividades que se someten al SEIA. Estas normas aún deben someterse a consulta a los pueblos indígenas para su aprobación, aunque a simple vista se observa que no cumplen los estándares establecidos por el Convenio $\mathrm{N}^{\circ} 169$, por cuanto tanto la Guía como el procedimiento no han sido resultado de un acuerdo entre las partes, no se contemplan en ellos los estándares mínimos exigidos por la consulta según el artículo 6 del Convenio (ya que el procedimiento no está orientado a construir consensos y acuerdos), se reducen a una mera encuesta, y los mecanismos y plazos no están previstos para ser aplicados en un contexto multicultural e inclusivo. Se puede consultar en 〈http://www.consultaindigena.cl/munitas/ME-Participacion-Indigena-SEA.pdf〉. 


\section{ANÁLISIS CRÍTICO DEL DECRETO SUPREMO Nº 124}

\section{Nociones preliminares}

Tras la ratificación por parte del Estado de Chile del Convenio $\mathrm{N}^{\circ} 169$ el 15 de septiembre de 2008, durante el período de vacancia legal de un año antes de que este entrara en vigencia ${ }^{40}$ el Poder Ejecutivo decidió regular la obligación estatal de escuchar los intereses de los pueblos indígenas establecida en la Ley $\mathrm{N}^{\circ} 19.253^{41}$ —mejor conocida como Ley Indígena - con vistas a crear un reglamento provisional sobre la materia para que entrara a regir conjuntamente con el Convenio.

El fruto de este trabajo fue el Decreto Supremo $N^{\circ} 124 / 2009^{42}$, del Ministerio de Planificación (MIDEPLAN), que creó el Reglamento ${ }^{43}$ del artículo 34 de la mencionada Ley $\mathrm{N}^{\mathrm{o}} 19.253^{44}$ a fin de regular la consulta y la participación de los pueblos indígenas. Este decreto se promulgó el 4 de septiembre de 2009 y entró en vigencia tras su publicación en el diario oficial el 25 de septiembre del mismo año, a poco más de una semana de que comenzara a regir plenamente el Convenio en Chile.

Esta norma administrativa ha sido objeto, desde el mismo momento de su creación, de severas críticas por parte de amplios sectores de la sociedad civil, las agrupaciones indígenas y la doctrina especializada, ya que las características de su aprobación, así

\footnotetext{
${ }^{40}$ El instrumento de ratificación de dicho Convenio se depositó con fecha 15 de septiembre de 2008 ante el director general de la Organización Internacional del Trabajo, y de conformidad con el artículo 38, párrafo 3, del Convenio $N^{\circ} 169$, entró en vigencia para Chile el 15 de septiembre de 2009. Vid. Decreto $\mathrm{N}^{\mathrm{o}}$ 236, de 2 de octubre de 2008, del Ministerio de Relaciones Exteriores de Chile, que promulga Convenio $\mathrm{N}^{\mathrm{o}} 169$ sobre Pueblos Indígenas y Tribales en Países Independientes de la Organización Internacional del Trabajo (DO 14/10/2008).

${ }^{41}$ Ley $\mathrm{N}^{\circ} 19.253$, que establece normas sobre protección, fomento y desarrollo de los indígenas, y crea la Corporación Nacional de Desarrollo Indígena (DO 05/10/1993).

${ }^{42}$ Decreto Supremo $\mathrm{N}^{\circ} 124$, que reglamenta el artículo 34 de la Ley $\mathrm{N}^{\circ} 19.253$ a fin de regular la consulta y la participación de los pueblos indígenas (DO 25/09/2009). En adelante, Decreto, Decreto $\mathrm{N}^{\circ} 124$ o DS 124 , indistintamente.

${ }^{43}$ Reglamento del artículo 34 de la Ley $\mathrm{N}^{\circ}$ 19.253, creado por el Decreto Supremo $\mathrm{N}^{\circ} 124$, en adelante, Reglamento.

${ }^{44}$ El artículo 34 de la Ley 19.253, que versa sobre la "participación indígena", establece la obligación de los órganos de la Administración del Estado de "escuchar y considerar" la opinión de las organizaciones indígenas: "Artículo 34.- Los servicios de la administración del Estado y las organizaciones de carácter territorial, cuando traten materias que tengan injerencia o relación con cuestiones indígenas, deberán escuchar y considerar la opinión de las organizaciones indígenas que reconoce esta ley. Sin perjuicio de lo anterior, en aquellas regiones y comunas de alta densidad de población indígena, éstos a través de sus organizaciones y cuando así lo permita la legislación vigente, deberán estar representados en las instancias de participación que se reconozca a otros grupos intermedios".
} 
como su contenido, han despertado suspicacias por cuanto pareciera que pretende conculcar el derecho a consulta y participación de los pueblos indígenas.

Como veremos a continuación, el Decreto $\mathrm{N}^{\circ} 124$ contraviene los estándares de aplicación de la consulta conforme a las normas de derecho internacional de pueblos indígenas y mina el carácter autoejecutable de este derecho fijado en su momento por el Tribunal Constitucional.

\section{Críticas al Decreto Supremo $N^{\circ} 124$}

Apenas entró en vigencia el Decreto $\mathrm{N}^{\circ} 124$, se hicieron patentes una serie de incongruencias, tanto formales como de fondo, que hicieron dudar a las agrupaciones del mundo indígena, a la sociedad civil organizada y a la doctrina especializada de la pertinencia de la normativa, así como de la voluntad política del Estado chileno de implementar el derecho de consulta a los pueblos indígenas de conformidad con los estándares mínimos fijados por el Convenio 169.

Como ya señalamos en un apartado anterior, el Convenio $\mathrm{N}^{\circ} 169$ de la OIT es un instrumento internacional ratificado por el Estado chileno y actualmente vigente que consagra derechos fundamentales, por lo que forma parte del ordenamiento jurídico interno con rango supralegal. En virtud de ello, conforme a lo que se señala en el artículo 5, inciso 2, de la Constitución ya analizado, la soberanía se encuentra limitada por los derechos esenciales que emanan de la naturaleza humana reconocidos en el Convenio, en este caso en particular, los estándares internacionales de derechos de pueblos indígenas y las disposiciones del Convenio 169 de la OIT.

En virtud de ello, los poderes del Estado están obligados a proteger y garantizar los derechos contenidos en el Convenio, "sin que sea posible su relativización por la vía de su interpretación restrictiva" ${ }^{45}$. Sin embargo, el nuevo Reglamento de consulta creado por el Decreto $\mathrm{N}^{\circ} 124$ impone una serie de restricciones al ámbito de aplicación del derecho de consulta contemplado en el Convenio, desvirtuando sus caracteres básicos.

\footnotetext{
${ }^{45}$ MEZA-LOPEHANDÍA, M. (2009), "El reglamento sobre consulta a pueblos indígenas propuesto por el Gobierno de Chile, la buena fe y el derecho internacional de los Derechos Humanos", p. 3. Recuperado el 2 de septiembre de 2011 de:

〈http://www.mapuexpress.net/images/publications/13_10_2009_21_55_57_1.pdf〉.
} 
A continuación señalaremos de manera sucinta cuáles han sido las principales críticas efectuadas al Decreto $\mathrm{N}^{\circ} 124^{46}$.

\subsection{Cuestionamientos de forma}

El Decreto $N^{\circ} 124$ se dictó incurriendo en una serie de irregularidades formales que, atendido el contexto en que se efectuó su aprobación y analizadas a la luz de los errores sustantivos que se verán más adelante, han permitido sostener que, desde su creación, el Estado chileno buscó dificultar una implementación adecuada del derecho a la consulta de los pueblos indígenas en conformidad con los estándares internacionales fijados por el derecho de los pueblos indígenas y el Convenio $\mathrm{N}^{\circ} 169$ de la OIT, en especial por haberse dictado sin consultar previamente a los pueblos indígenas e intentando impedir la autoejecutabilidad de la consulta.

\section{A. Decreto $\mathrm{N}^{\circ} 124$, dictado sin procedimiento de consulta previa}

El Decreto se dictó sin efectuarse un procedimiento de consulta previa a los pueblos indígenas a través de sus organizaciones representativas. Este hecho contraviene la recomendación explícita en ese sentido hecha al Estado por el propio relator especial de Naciones Unidas sobre la situación de los derechos humanos y las libertades fundamentales de los indígenas, James Anaya, en su informe de 2009 "La situación de

\footnotetext{
${ }^{46}$ Seguiremos en este apartado los apuntes críticos contenidos en CONAPACH (2010, 1 de septiembre), "Informe Alternativo 2010 respecto del cumplimiento del Convenio 169 sobre Pueblos Indígenas y Tribales de la OIT, al cumplirse un año de su entrada en vigencia en Chile". Recuperado el 1 de septiembre de 2011 de: 〈http://www.derechoshumanos.udp.cl/wp-content/uploads/2010/10/memoriaalternativa-convenio-169-oit-chile-2010-1.pdf). Este informe, redactado colectivamente por el Consejo de Longko del Pikun Wijimapu, el Centro de Derechos Humanos de la Universidad Diego Portales, el Grupo de Trabajo Mapuche sobre los Derechos Colectivos, el Observatorio Ciudadano y Wallmapuwen, fue presentado ante la OIT con objeto de ofrecer un diagnóstico en torno al estado actual de la aplicación e implementación del Convenio 169 de la OIT en su primer año de vigencia en Chile, con objeto de contraponerse al informe oficial del Gobierno: GOBIERNO DE CHILE (2010, 1 de septiembre), Memoria presentada por el Gobierno de Chile en conformidad con las disposiciones del artículo 22 de la Constitución de la Organización Internacional del Trabajo correspondiente al período de 15 de septiembre de 2009 al 15 de septiembre de 2010 acerca de las medidas adoptadas para dar efectividad a las disposiciones del Convenio sobre Pueblos Indígenas y Tribales, 1989 (NÚM. 169), ratificado por Chile el 15 de septiembre de 2008. Recuperado el 1 de septiembre de 2011 de: http://www.derechoshumanos.udp.cl/wp-content/uploads/2010/10/memoria-oficial-convenio-169-oit$1 \mathrm{c} 2 \mathrm{~b} 0$-septiembre-2010.pdf).
}

Además, contemplamos las observaciones contenidas en: Instituto Nacional de Derechos Humanos (2010), "Informe Anual 2010: Situación de los Derechos Humanos en Chile". Recuperado el 1 de septiembre de 2011 de: http://www.indh.cl/primer-informe-anual-2010-de-derechos-humanos-en-chile; MEZA-LOPEHANDÍA, M., "El reglamento...", cit., y TOLEDO LLANCAQUEO, V. (2009), Texto comentado del Decreto 124 de 'Reglamento de Consulta y Participación de los pueblos indígenas en Chile', recuperado el 28 de agosto de 2011 de: http://www.politicaspublicas.net/panel/imp/392-decreto124.htmls. 
los Pueblos Indígenas en Chile: seguimiento de las recomendaciones hechas por el Relator anterior".

En efecto, el relator indicó la necesidad de efectuar una verdadera "consulta sobre la consulta" con el objeto de "determinar el procedimiento para implementar en Chile los estándares internacionales en las consultas propiamente dichas, antes de la adopción de cualquier medida que afecte directamente a los pueblos indígenas o a una comunidad indígena"47. Más aún, dado que el Gobierno de Chile había informado al relator de la existencia del proyecto de Reglamento destinado a regular provisionalmente las obligaciones contenidas en los artículos 6 y 7 del Convenio y en el artículo 34 de la Ley Indígena, el relator señaló específicamente la obligación de someter a consulta esta norma administrativa antes de su adopción ${ }^{48}$.

Peor aún: el legislador chileno citó al propio relator especial de Naciones Unidas en el considerando noveno del Decreto que crea el Reglamento para justificar la aplicación de este mecanismo transitorio para un ejercicio efectivo de la consulta ${ }^{49}$, lo cual contraviene la recomendación explícita de James Anaya a la que hemos hecho referencia respecto a la obligatoriedad de la consulta previa del Reglamento sobre consulta, respetándose los estándares mínimos establecidos en las normas internacionales ${ }^{50}$.

\footnotetext{
47 Relator especial de Naciones Unidas sobre la situación de los derechos humanos y las libertades fundamentales de los indígenas, ANAYA, J. (2009, 14 de septiembre), "La situación de los Pueblos Indígenas en Chile: seguimiento de las recomendaciones hechas por el Relator anterior", A/HRC/12/34/Add.6, párr. 11. Recuperado el 8 de septiembre de 2011 de: 〈http://unsr.jamesanaya.org/esp/docs/countries/2009_report_chile_sp.pdf〉.

48 “ [...] el Relator Especial enfatiza que tal reglamento debe ser consultado previamente con los pueblos indígenas del país y debe contemplar los requisitos esenciales de la consulta establecidos en las normas internacionales". Relator especial de Naciones Unidas, ANAYA, J., "La situación de los Pueblos...", cit., párr. 12.

${ }^{49}$ El Decreto en su considerando noveno establece que "el Relator Especial de Naciones Unidas sobre la situación de los derechos humanos y las libertades fundamentales de los indígenas ha señalado que, en aquellos casos en que los mecanismos para llevar a cabo la consulta no existan formalmente, deberán adoptarse provisionalmente mecanismos transitorios con miras al ejercicio efectivo de ésta". Esta remisión que el legislador hace al informe del relator especial de Naciones Unidas, ANAYA, J., "Principios Internacionales...", cit., para justificar la adopción de un reglamento inconsulto sobre la consulta es un ejemplo claro de la escasa voluntad política para cumplir de forma fehaciente los estándares internacionales del derecho de los pueblos indígenas.
}

50 Sobre este tema se manifestó el "Informe Alternativo 2010": "Si bien explícitamente el Relator Especial para Pueblos Indígenas de la ONU, James Anaya, en el párrafo 38 de su Informe sobre 'Principios Internacionales Aplicables a la Consulta en Relación con la Reforma Constitucional' señaló que en los casos que no existan mecanismos formales de consulta, se debían adoptar provisionalmente mecanismos transitorios o ad-hoc con miras al ejercicio efectivo de la consulta indígena, dicho principio en nada justifica la existencia del DS 124. Esto por cuanto, según aclara el mismo Anaya, las condiciones para efectuar estos procedimientos transitorios, es que se encuentren de acuerdo con los estándares 
Al respecto, Bartolomé Clavero ha señalado que las declaraciones del relator especial vertidas en el documento "Principios internacionales aplicables a la consulta en relación con la reforma constitucional en materia de derechos de los pueblos indígenas en Chile", sobre la aplicación de mecanismos transitorios, deben entenderse insertas dentro del proceso gradual y progresivo de diálogo normativo en torno a las demandas legítimas de los pueblos indígenas en un contexto "de buena fe" entre las partes ${ }^{51}$. Según señala Clavero, en ese contexto "lo que en ningún momento el Relator admite ni por asomo es que dicho establecimiento inicial de 'mecanismos transitorios' pueda llevarse a cabo sin efectuarse consulta. El Reglamento falta a la verdad de modo deliberado cuando afirma otra cosa" ${ }^{\natural 2}$.

B. Críticas a la oportunidad y celeridad del procedimiento de aprobación

El Decreto analizado se promulgó el 4 de septiembre de 2009 y entró en vigencia tras su publicación en el diario oficial el 25 de septiembre de 2009, a poco más de una semana de que comenzara a regir plenamente el Convenio $\mathrm{N}^{\circ} 169$ en Chile. El Estado chileno justificó la celeridad de la aprobación del Reglamento sobre la consulta en base a una razón de urgencia admitida en el considerando noveno del Decreto, como hemos visto, citando erróneamente al propio relator especial para justificar la dictación de un reglamento inconsulto.

A nuestro entender, las razones subyacentes son otras. Más bien pareciera que mediante la dictación del Reglamento, muy cercana en el tiempo a la entrada en vigor del Convenio $\mathrm{N}^{\circ} 169$, se ha buscado restringir la implementación adecuada de las normas internacionales de derecho de los pueblos indígenas, restándole efectividad a la

\footnotetext{
internacionales en materia de consulta. Así debe entenderse, por lo demás, el margen de discrecionalidad que el Convenio otorga a los estados en virtud de su art. 34, esto es, que se pueden aplicar con flexibilidad las medidas del convenio 'en la medida en que las Partes hagan uso de dicha flexibilidad sin dejar de cumplir con el objeto esencial de sus obligaciones que, en este caso, consiste en asegurar la efectiva participación de los grupos étnicos en las decisiones que les conciernan', como lo ha señalado la Corte Constitucional colombiana". CONAPACH, "Informe Alternativo 2010 respecto...", cit., p. 50. En el mismo sentido, Instituto Nacional de Derechos Humanos, "Informe Anual 2010...”, cit., p. 101.

${ }^{51}$ Vid. CLAVERO SALVADOR, B. (2009, 18 de septiembre), "Puesta en Práctica de Convenio o Puesta en Evidencia de Chile (Por los Informes del Relator Anaya)". Recuperado el 28 de agosto de 2011 de: http://clavero.derechosindigenas.org/?p=3313.

${ }^{52}$ CLAVERO SALVADOR, B., "Puesta en Práctica...", cit.
} 
consulta $^{53}$ y limitando la naturaleza de autoejecutable reconocida por el Tribunal Constitucional.

Como veremos más adelante, el contenido del Decreto limita enormemente el derecho de consulta del Convenio $\mathrm{N}^{\mathrm{o}}$ 169. Por lo tanto, no parece mera coincidencia que justamente en la fecha en que entra en vigor el Convenio $\mathrm{N}^{\circ} 169$ en Chile se promulga el Reglamento sobre el artículo 34 de la Ley Indígena que regula la participación indígena, haciéndolo extensible para controlar la consulta del Convenio. Como señala Bartolomé Clavero, esta cercanía en los tiempos pareciera existir tan solo "para reservarse mecanismos de control de futuras consultas" $" 54$ por parte del legislador.

Se ha entendido ${ }^{55}$ que la celeridad en su aprobación pareciera estar en franca oposición con el principio básico del derecho internacional que insta a los Estados a abstenerse de frustrar el objeto y el fin de un tratado cuando hayan manifestado su consentimiento a obligarse a este, sobre todo durante el período que precede a su entrada en vigor, según lo que establece el artículo 18 de la Convención de Viena sobre el Derecho de los Tratados de 1969.

\section{Críticas al pretendido carácter provisional}

El artículo transitorio del Reglamento establece que, una vez este haya entrado en vigencia, se dará inicio a un proceso de consulta a los pueblos indígenas acerca del procedimiento para llevar a cabo los procesos de consulta y participación en conformidad con lo establecido en la Ley Indígena y en los artículos que regulan la consulta en el Convenio $\mathrm{N}^{\mathrm{o}} 169^{56}$.

\footnotetext{
${ }^{53}$ Respecto a la oportunidad en que se ha aprobado este reglamento, Montt y Matta han señalado que "el citado Reglamento aparece como un absurdo intento de última hora por burlar el derecho de participación de los pueblos indígenas", MONTT OYARZÚN, S., y MATTA AYLWIN, M., "Una visión...", cit., p. 197. Respecto a este mismo asunto, vid. MEZA-LOPEHANDÍA, M., "El reglamento...", cit., TOLEDO LLANCAQUEO, V., "Texto comentado...", cit., y CLAVERO SALVADOR, B., "Puesta en Práctica...", cit.

${ }^{54}$ CLAVERO SALVADOR, B., "Puesta en Práctica...", cit.

${ }^{55}$ Cfr. MEZA-LOPEHANDÍA, M., “El reglamento...”, cit., pp. 1 y ss.

56 “Artículo transitorio: Una vez que entre en vigencia el presente reglamento, se dará inicio a un proceso de consulta a los pueblos indígenas acerca del procedimiento para llevar a cabo los procesos de consulta y participación en conformidad a lo establecido en el artículo 34 de la ley $\mathrm{N}^{\circ} 19.253$ y en los artículos $6 \mathrm{~N}^{\circ}$ 1 letra a) y $\mathrm{N}^{\circ} 2$, y $7 \mathrm{~N}^{\circ} 1$ oración segunda del Convenio $\mathrm{N}^{\mathrm{o}} 169$ de la Organización Internacional del Trabajo". Decreto Supremo N 124, que reglamenta el artículo 34 de la Ley N 19.253.
} 
Con esta disposición se debería entender que el Reglamento tiene carácter provisional; sin embargo, como sostiene Matías Meza-Lopehandía, "su redacción y contenido no reflejan dicha provisionalidad"57, ya que no regula un proceso específico de consulta limitado en tiempo y forma, sino que es una norma establecida de forma genérica que busca regular el proceso de la consulta y también la participación de forma indefinida.

Como ejemplo de lo anterior se ha señalado que el Reglamento no fija un plazo o condición para su aplicación transitoria, de manera que se establezca claramente su período de vigencia y su reemplazo por normas permanentes de aplicación general, y, además, en sus disposiciones pretende regular cuestiones generales como la competencia para definir la pertinencia de la consulta, lo cual es manifestación de que el Reglamento no reviste visos de provisionalidad ${ }^{58}$.

\subsection{Cuestionamientos de fondo}

Las severas limitaciones a los principios mínimos aplicables al derecho de consulta que el Decreto $\mathrm{N}^{\circ} 124$ efectúa al implementar el Convenio $\mathrm{N}^{\circ} 169$ se manifiestan de diversas maneras. Por una parte, el Decreto restringe las medidas susceptibles de someterse a consulta dependiendo del tipo de órgano administrativo o legislativo del cual emana el acto susceptible de ser consultado; por otra, limita su aplicación dependiendo del objeto o materia sobre la cual recae el acto, $\mathrm{y}$, por último, resta obligatoriedad a la consulta atendiendo a la naturaleza del acto o la medida administrativa a consultar, de cuya naturaleza dependerá si se le aplica de forma obligatoria o no la consulta.

Todas estas restricciones son una abierta violación a las normas del Convenio $\mathrm{N}^{\circ} 169$, ya que como se verá a continuación no se trata de limitaciones acotadas, sino que, por el contrario, se excluye de la obligatoriedad del trámite de la consulta previa de buena fe un espectro amplio de actos y medidas administrativas que por lo general son los más susceptibles de provocar impacto sobre el medio ambiente, el territorio y los recursos naturales en comunidades indígenas.

\footnotetext{
${ }^{57}$ MEZA-LOPEHANDÍA, M., “El reglamento...”, cit., p. 2.

${ }^{58}$ Vid. MEZA-LOPEHANDÍA, M., “El reglamento...”, cit., pp. 2 y ss.
} 
A. Equiparación de estándares de consulta

Una limitación flagrante a los principios mínimos aplicables al derecho de consulta se encuentra en lo establecido en el artículo 1 del Reglamento, que señala que su objeto es regular la obligación de los órganos de la Administración del Estado de "escuchar y considerar" la opinión de las organizaciones indígenas cuando traten materias que tengan injerencia o relación con cuestiones indígenas, obligación establecida en el artículo 34 de la Ley N 19.253, "materializando" dicha obligación en la consulta y la participación de los pueblos indígenas consagradas en el artículo $6, \mathrm{n}^{\mathrm{o}} 1$, letra a), y $\mathrm{n}^{\mathrm{o}} 2$, y en el artículo $7, \mathrm{n}^{\mathrm{o}} 1$, oración final del Convenio $\mathrm{N}^{\mathrm{o}} 169^{59}$.

De la lectura de esta disposición se desprende que el Decreto está contraviniendo el Convenio $\mathrm{N}^{\circ} 169$. En efecto, la regulación, más que centrarse en fijar el procedimiento de consulta dentro del marco de la Ley No 19.253 (Ley Indígena), sobrepasa esos límites al regular el derecho de consulta del Convenio $\mathrm{N}^{\circ} 169$ y proceder a equiparar los estándares de consulta del artículo 34 de la Ley Indígena, limitado a "escuchar y considerar" las inquietudes de los pueblos indígenas, con los estándares mucho más exigentes del Convenio.

De esta manera, el legislador está desconociendo el carácter de la consulta como un deber estatal orientado a obtener de buena fe el consentimiento de los pueblos indígenas respecto de las medidas susceptibles de afectar a sus intereses y permitirles una participación efectiva en el proceso de gestación y toma de decisiones de la Administración, y lo está reduciendo a un mero mecanismo de información.

Además, con esta equiparación se está limitando enormemente el derecho de consulta del Convenio, ya que como veremos más adelante los criterios de implementación de la consulta en el Decreto $\mathrm{N}^{\circ} 124$ contienen una serie de restricciones a la participación y a la consulta en temas sustanciales para la tutela del territorio y los recursos naturales de

\footnotetext{
59 “Artículo $1^{\text {o }}$.- Objeto del reglamento. El presente reglamento regula la obligación de los órganos de la administración del Estado de escuchar y considerar la opinión de las organizaciones indígenas cuando traten materias que tengan injerencia o relación con cuestiones indígenas, establecida en el artículo 34 de la ley $\mathrm{N}^{\mathrm{o}} 19.253$.

Dicha obligación se materializa en la consulta y la participación de los pueblos indígenas consagradas en el artículo $6 \mathrm{~N}^{\circ} 1$ letra a) y $\mathrm{N}^{\circ} 2$ y en el artículo $7 \mathrm{~N}^{\mathrm{o}} 1$ oración final del Convenio $\mathrm{N}^{\mathrm{o}} 169$ de la Organización Internacional del Trabajo sobre Pueblos Indígenas y Tribales en Países Independientes, promulgado por medio del decreto supremo No 236, de 2008, del Ministerio de Relaciones Exteriores". Decreto Supremo $\mathrm{N}^{\circ} 124$, que reglamenta el artículo 34 de la Ley $\mathrm{N}^{\circ} 19.253$.
} 
los pueblos indígenas, como es el caso de los proyectos de inversión o la aplicación facultativa de la consulta en cuestiones de gobierno local.

Por otro lado, resulta altamente sospechoso que se regule por este Reglamento específicamente el derecho de consulta en aquellos puntos que el Tribunal Constitucional declaró como autoejecutables, o sea, conforme a lo que vimos en su oportunidad, aplicables sin necesidad de un acto legislativo posterior.

Si a ello agregamos que, según señaló el Tribunal Constitucional, la obligación contenida en el artículo 6 del Convenio es esencialmente distinta de las del artículo 34 de la Ley Indígena por tratarse de una norma que "tiene una connotación jurídica especial" ${ }^{60}$ conforme a lo que establece el artículo 6, número 2 , del Convenio 169 —que exige que deben efectuarse de buena fe, de una manera apropiada y con la finalidad de lograr el consentimiento acerca de las medidas propuestas-, no es factible la equiparación de estándares que pretende el legislador.

La doctrina ha postulado que, dado que el Convenio 169 tiene jerarquía de norma fundamental conforme al artículo 5, inciso segundo, de la Constitución y se ha integrado en el sistema normativo chileno, al entrar en vigencia tácitamente derogó la norma del artículo 34 de la Ley Indígena ${ }^{61}$. Por ello es posible sostener, como han hecho Santiago Montt y Manuel Matta, que "el nuevo reglamento, que intenta ejecutar una norma legal parcialmente derogada, corre el serio riesgo de ser nulo de nulidad de Derecho público" ${ }^{\circ 2}$.

En materia ambiental se ha intentado asimilar los procedimientos de participación ciudadana en este ámbito contemplados dentro de la normativa común del Sistema de Evaluación de Impacto Ambiental (SEIA), e incluso otras instancias de participación, con los procedimientos de consulta previa del Convenio 169. Pero desde la entrada en vigencia del Convenio la doctrina y la jurisprudencia reciente han confirmado el carácter diferenciado y especial de la consulta, por lo que esta equiparación no es

\footnotetext{
${ }^{60}$ TRIBUNAL CONSTITUCIONAL, Fallo 309, año 2000, considerando $7^{\circ}$.

${ }^{61}$ Montt y Matta han señalado al respecto que el Convenio $\mathrm{N}^{\mathrm{o}} 169$ introduce importantes innovaciones respecto al derecho a la participación contemplado en la Ley Indígena 19.253, de 1993, lo que permite sostener que, dado que la "Ley No 19.253 no pasa los estándares del Convenio 169 —al menos parcialmente-, debe concluirse que es el propio Convenio el que rige en calidad de lex posteriori. Más aún, en cuanto tratado de derechos humanos, el Convenio 169 es inderogable y no-inaplicable tanto por el legislador como por los tribunales (salvo el Tribunal Constitucional en sede de inaplicabilidad por inconstitucionalidad)”. MONTT OYARZÚN, S., y MATTA AYLWIN, M., “Una visión...”, cit., p. 196.

${ }^{62}$ MONTT OYARZÚN, S., y MATTA AYLWIN, M., “Una visión...”, cit., p.197.
} 
posible. Además de la sola lectura del proceso de participación ciudadana del SEIA de la Ley 19.300, se observa que no se cumplen los estándares de la consulta establecidos por el Convenio en cuanto a los plazos, las oportunidades y las formas de participación ${ }^{63}$.

B. Limitación de la aplicación y obligatoriedad de la consulta

B.1. Según el órgano del cual emana el acto o medida

El Convenio no distingue el tipo de órgano estatal encargado de enunciar las medidas administrativas o legislativas, sino que basta con que revistan tal carácter para estar sujetas a consulta ${ }^{64}$. El Reglamento, en cambio, restringe el ámbito de aplicación de la consulta al establecer que solo serán susceptibles de consulta aquellas medidas que tengan origen en alguno de los órganos de la Administración del Estado señalados en el artículo 4, tales como los ministerios, las intendencias, las gobernaciones, las fuerzas armadas, las fuerzas de orden y seguridad pública, los servicios públicos creados para el cumplimiento de la función administrativa y el Consejo para la Transparencia, excluyendo unilateralmente de su aplicación a los órganos "constitucionalmente autónomos" como las municipalidades y a las empresas públicas creadas por el Estado, para quienes será facultativa su aplicación ${ }^{65}$.

De esta manera, al limitarse la obligatoriedad de la consulta, permitiendo su aplicación de forma facultativa a los órganos encargados de la Administración local como son las municipalidades o las empresas públicas creadas por ley, se incurre en un contrasentido por cuanto estos órganos son precisamente aquellos más susceptibles de adoptar medidas que afecten al territorio y los recursos naturales en territorio de comunidades indígenas. Por ello el Informe señala que esta norma “deja en grave indefensión a los pueblos indígenas pues varios de estos órganos tienen particular incidencia en decisiones que los pueden afectar directamente" ${ }^{\text {. }}$.

${ }^{63}$ Para un análisis detallado de la consulta en el SEIA, vid. PRECHT RORRIS, A., y AYLWIN CORREA, S., "Entrada en vigencia del Convenio 169: El proceso de consulta de los pueblos indígenas y los proyectos sometidos al SEIA", Durán Medina, V. et ál. (eds.), Derecho ambiental, en tiempos de reformas. Actas de las V Jornadas de Derecho Ambiental, Abeledo-Perrot, Santiago, 2010.

${ }^{64}$ Artículo 6, n 1 , Convenio $\mathrm{N}^{\circ} 169$ OIT.

${ }^{65}$ Artículo 4, Reglamento del artículo 34 de la Ley $\mathrm{N}^{\circ} 19.253$, creado por el Decreto Supremo $\mathrm{N}^{\circ} 124$.

${ }^{66}$ CONAPACH, "Informe Alternativo 2010 respecto..., cit., p. 86. 
Esta situación ha sido una de las más criticadas por la doctrina, y según señala MezaLopehandía, estamos claramente ante una flagrante violación del Convenio, e incluso más, que la "exclusión por la vía reglamentaria de la aplicación de las normas de consulta y participación del Conevnio [sic.] 169 a ciertos órganos del Estado y a las empresas públicas resulta ilegal, toda vez que no existen dudas sobre su vigencia y exigibilidad en el derecho interno" ${ }^{\text {67. }}$.

\section{B.2. Según la materia: caso de los proyectos de inversión}

El Decreto excluye los proyectos de inversión de la obligatoriedad de la consulta previa a los pueblos indígenas. El artículo 5 del Reglamento creado por el Decreto 124 remite en esta materia "a los procedimientos de consulta y participación que se contemplan en las respectivas normativas sectoriales ${ }{ }^{68}$, siendo facultativo para el órgano sectorial que emite la medida el someterse a los procedimientos de consulta contemplados en el Reglamento.

Esta disposición, además de contravenir la obligatoriedad de la consulta, relativiza el carácter autoejecutable de la norma desatendiendo la decisión del Tribunal Constitucional que señaló expresamente que la obligación de consulta del Convenio difiere sustancialmente de "aquellas otras que se establecen en el actual ordenamiento positivo" ${ }^{\circ 9}$, reenviando la consulta a mecanismos que no responden a los estándares del Convenio 169.

Se señala en el artículo 5 del Decreto que para los proyectos de inversión en las tierras o áreas de desarrollo indígena — definidas en la Ley Indígena- se regula la consulta o participación conforme a lo preceptuado en las respectivas normas sectoriales, siendo facultativo para el órgano de la Administración del Estado someterse a este procedimiento; en este último caso, el proceso de consulta se ajustará a los plazos establecidos en la normativa sectorial ${ }^{70}$.

\footnotetext{
${ }^{67}$ MEZA-LOPEHANDÍA, M., "El reglamento...”, cit., p. 4.

${ }^{68}$ Artículo 5, Reglamento del artículo 34 de la Ley N 19.253, creado por el Decreto Supremo $N^{\circ} 124$.

${ }^{69}$ MEZA-LOPEHANDÍA, M., "El reglamento...”, cit., p. 5.

${ }^{70}$ Artículo 5, Reglamento del artículo 34 de la Ley $N^{\circ}$ 19.253, creado por el Decreto Supremo $N^{\circ} 124$.
} 
Conforme a la Ley 19.300, todos los proyectos de inversión que puedan afectar al medio ambiente ${ }^{71}$ deben someterse a una evaluación de impacto ambiental, sea a través de una declaración de impacto ambiental (DIA) o de un estudio de impacto ambiental (EIA) cuando los efectos sobre el ambiente sean de mayor envergadura.

Pero dado que, por la remisión del artículo 5 del Reglamento a la normativa sectorial, solo los proyectos que entren a evaluación por EIA son susceptibles de ser sometidos a las normas de consulta y participación de la normativa ambiental, todos aquellos proyectos que sean evaluados por una DIA quedarán excluidos de la consulta ${ }^{72}$. Esto es especialmente grave en materia ambiental por cuanto significará la exclusión de la aplicación de la consulta a un número significativo de proyectos de inversión, vulnerándose los derechos colectivos de pueblos indígenas sobre su territorio y recursos naturales.

El Informe del INDH señala al respecto que "[1]a expresa exclusión de los proyectos de inversión constituye una grave omisión, particularmente porque las principales tensiones con las comunidades indígenas se producen por la expansión de megaproyectos energéticos, mineros, de acuicultura y forestación. Estos quedan sujetos a la consulta ciudadana establecida en la regulación sectorial, y es facultativo para el órgano sectorial que emite la medida adoptar el al [sic.] procedimiento contemplado en el Decreto Supremo"73.

\section{B.3. Según el tipo de acto o medida administrativa de que se trate}

Las medidas a ser consultadas son, según señala el artículo 14 del Reglamento creado por el Decreto $\mathrm{N}^{\circ} 124$, las de carácter administrativo o legislativo que tengan su origen

\footnotetext{
${ }^{71}$ En Chile la definición legal de medio ambiente de la Ley 19.300 es un concepto amplio que abarca conceptos socioculturales. Según el artículo 2, letra 11): "Medio Ambiente: el sistema global constituido por elementos naturales y artificiales de naturaleza física, química o biológica, socioculturales y sus interacciones, en permanente modificación por la acción humana o natural y que rige y condiciona la existencia y desarrollo de la vida en sus múltiples manifestaciones". En atención a este concepto sumamente amplio, que comprende elementos naturales, artificiales y socioculturales, se entiende que forman parte de él el patrimonio histórico, artístico, cultural, antropológico o arqueológico, y, por ende, es posible vincular la protección de intereses de los pueblos indígenas a través de la normativa de protección del medio ambiente.

72 Existen diferentes interpretaciones, tanto en sede judicial como administrativa, del modo y la aplicabilidad del proceso de consulta a proyectos que ingresan al SEIA, tanto en el caso de las DIA como en los EIA, y falta un pronunciamiento claro sobre la materia por parte de la autoridad. Para profundizar en este aspecto, vid. PRECHT RORRIS, A., y AYLWIN CORREA, S., "Entrada en vigencia...", cit., pp. 446 y ss.

${ }^{73}$ Instituto Nacional de Derechos Humanos, “Informe Anual 2010...”, cit., p. 101.
} 
en los órganos de la Administración del Estado, que, como señalamos, son los que el propio Decreto delimita ${ }^{74}$.

Se entiende por medidas legislativas, al tenor de lo señalado en el Reglamento en su artículo 14, las "ideas matrices de los proyectos de reforma constitucional y de los proyectos de ley, así como los reglamentos" ${ }^{27}$. Esta norma restringe la aplicación de procesos de consulta de buena fe en materia legislativa, ya que la limita solo a las fases iniciales del desarrollo normativo. Esta circunstancia contraviene expresamente lo dispuesto por el relator especial, quien ha señalado al respecto que "los pueblos indígenas deberán ser consultados previamente en todas las fases del proceso de producción normativa, y dichas consultas no deben ser restringidas a propuestas iniciales siempre que tengan relación con las ideas matrices de la medida en cuestión" ${ }^{, 76}$. Respecto a las medidas administrativas a las que les es aplicable el trámite de consulta, el nuevo Reglamento las limita a las "políticas, planes y programas elaborados por los órganos de la administración del Estado" que "afecten directamente a los pueblos indígenas", y sobre las cuales estos órganos consideren "pertinente" consultar ${ }^{77}$.

Conforme a lo expuesto, se ha señalado que con esta disposición el Estado chileno ha querido eximir de la consulta los llamados "actos administrativos" "78, es decir, según el artículo 3, inciso $2^{\circ}$, de la Ley 19.880 sobre Procedimiento Administrativo, "las decisiones formales que emitan los órganos de la Administración del Estado en las cuales se contienen declaraciones de voluntad, realizadas en el ejercicio de una potestad pública”.

Al eliminar la exigencia de la consulta respecto de los actos administrativos, se está limitando claramente la efectividad de esta, ya que debe tenerse en cuenta el hecho de que "son precisamente las decisiones de los órganos estatales las que mayor afectación causan a los pueblos indígenas, se sustrae entonces del procedimiento de consulta a una

\footnotetext{
${ }^{74}$ Vid párrafo supra.

${ }^{75}$ Artículo 14, Reglamento del artículo 34 de la Ley $\mathrm{N}^{\circ}$ 19.253, creado por el Decreto Supremo $\mathrm{N}^{\circ} 124$.

${ }^{76}$ Relator especial de Naciones Unidas, ANAYA, J., "Principios Internacionales...”, cit., párr. 20.

77 Vid. artículo 14, inciso 3, Reglamento del artículo 34 de la Ley $\mathrm{N}^{\circ}$ 19.253, creado por el Decreto Supremo $\mathrm{N}^{\circ} 124$.

${ }^{78}$ CONAPACH, “Informe Alternativo 2010 respecto...”, cit., p. 52.
} 
gran cantidad de medidas que, por ser específicamente 'actos', no cabrían dentro de la definición del DS 124,79.

En materia ambiental se ha discutido si la denominada resolución de calificación ambiental (RCA), que es pronunciada por la Comisión Regional del Medio Ambiente (COREMA) y que califica ambientalmente una declaración de impacto ambiental o un estudio de impacto ambiental, reviste o no la naturaleza de medida administrativa.

El Reglamento al parecer contempla la resolución como un "acto administrativo", por lo que no constituiría una "medida administrativa" para efectos del artículo 14 del Decreto Supremo, y, consecuentemente, no estaría sujeta a la obligación de consulta, tal como lo asevera la jurisprudencia ${ }^{80}$. Sin embargo, la doctrina ${ }^{81}$ ha intentado morigerar esta interpretación, aduciendo una concepción amplia de "medida administrativa" con objeto de cumplir la finalidad de consulta del Convenio.

C. Limitación de la oportunidad y plazo para realizar la consulta

El Decreto establece una diferencia entre medidas legislativas y administrativas en cuanto a la oportunidad para realizar la consulta.

Para las medidas legislativas se establece una distinción entre ideas matrices de proyectos de reforma constitucional y proyectos de ley y normas de carácter reglamentario. Tratándose de proyectos de reforma constitucional o de ley, la consulta podrá realizarse previamente al envío al Congreso o durante su tramitación legislativa, lo que contraviene expresamente las recomendaciones del relator especial, que ha señalado que "[e]l carácter previo de la consulta exige que la nueva medida legislativa objeto de la consulta a los pueblos indígenas sea consultada en las fases previas a su tramitación parlamentaria" ${ }^{\text {}}$. Respecto de los reglamentos, la consulta deberá realizarse antes de su promulgación; en ambos casos, siempre que "la urgencia de la materia así lo permita".

\footnotetext{
${ }^{79}$ Ídem, p. 52.

${ }^{80}$ Caso Puelman Nanco Mariano y otro contra Comisión Regional del Medio Ambiente, Región de la Araucanía, CA Temuco, Rol N 1705-2009.

${ }^{81}$ Vid. PRECHT RORRIS, A., y AYLWIN CORREA, S., “Entrada en vigencia...”, cit., pp. 450 y ss.

${ }^{82}$ Relator especial de Naciones Unidas, ANAYA, J., “Principios Internacionales...”, cit., párr. 57.
} 
En cambio, para las medidas administrativas, el artículo 15, incisos primero y segundo, señala que la consulta deberá realizarse de forma previa a la aplicación de las nuevas políticas, planes o programas, salvo que, a causa de una emergencia o de las necesidades de buen funcionamiento del respectivo órgano, este disponga fundadamente lo contrario $^{83}$. Como vemos, es posible para el órgano administrativo eliminar el carácter previo de la consulta bajo ciertas circunstancias.

Agrega la norma que será el propio órgano de la Administración del Estado el encargado de determinar los instrumentos y las modalidades que permitan dar cumplimiento a los objetivos del proceso de consulta, los contenidos de la propuesta de medida legislativa o administrativa, así como el itinerario, los plazos y las actividades de dicho proceso ${ }^{84}$. Para estos efectos el Decreto establece un plazo máximo de 30 días para recibir las observaciones formuladas por las comunidades en el proceso de consulta.

Como se puede advertir, los plazos establecidos por el Decreto son absolutamente restrictivos e insuficientes para llevar a cabo un proceso de consulta adecuado, esencialmente dada la naturaleza y envergadura de las materias puestas a consideración de las comunidades indígenas, conforme a lo que se expresa en el Informe 2010 del Instituto Nacional de Derechos Humanos ${ }^{85}$. Asimismo, se constata que en el procedimiento propuesto no existe un espacio real para el diálogo de buena fe, tal como exige el Convenio, que permita alcanzar el consentimiento de los pueblos afectados por las medidas propuestas.

Por otro lado, conforme a lo dispuesto en los artículos 16 y 21 del Reglamento, la pertinencia de iniciar el proceso de consulta o participación se otorga a la autoridad u organismo de origen de la medida, junto con el Ministerio de Planificación y en coordinación con el Ministerio Secretaría General de la Presidencia ${ }^{86}$. Es decir, será entonces el propio órgano que dicta la medida el que debe asegurar la consulta o participación, y, por lo tanto, también está facultado para omitir discrecionalmente dicho trámite.

\footnotetext{
${ }^{83}$ Artículo 15, Reglamento del artículo 34 de la Ley No 19.253, creado por el Decreto Supremo No 124.

${ }^{84}$ Artículos 17 y 18, Reglamento del artículo 34 de la Ley $N^{\circ} 19.253$, creado por el Decreto Supremo $N^{\circ}$ 124.

${ }^{85}$ Instituto Nacional de Derechos Humanos, “Informe Anual 2010...", cit., p. 101.

${ }^{86}$ Artículos 16 y 21, Reglamento del artículo 34 de la Ley $\mathrm{N}^{\circ} 19.253$, creado por el Decreto Supremo $\mathrm{N}^{\circ}$ 124.
} 
Por último, conforme a lo que se explicita en el "Informe Alternativo"87, el Decreto hace incompatible la consulta con la participación, contraviniendo expresamente lo dispuesto en el Convenio 169, en el que es imposible disociar la consulta de la participación por cuanto aquella se entiende como la máxima expresión de esta ${ }^{88}$. En este sentido, el Decreto, además de restringir el concepto de medida administrativa del Convenio, en su artículo 14, inciso 3, excluye del proceso de consulta los planes y programas de desarrollo nacional o regional, los cuales solo podrán ser sometidos a un proceso de participación si el Estado así lo estima conveniente ${ }^{89}$.

\section{Fracaso de la implementación de la consulta del Decreto Supremo No 124}

Desde la misma entrada en vigor del Decreto Supremo No 124 se alzaron voces en su contra que pusieron de manifiesto las evidentes contravenciones al derecho internacional de los pueblos indígenas y al Convenio $\mathrm{N}^{\mathrm{o}} 169$. La evidencia del fracaso de la implementación durante el primer año de vigencia del Convenio se plasma en el "Informe de Observaciones sobre el cumplimiento del Convenio 169 en Chile", que con fecha 16 de febrero publicó la Comisión de Expertos en Aplicación de Convenios de la OIT (CEACR) como parte de su Informe Anual $2011^{90}$.

\footnotetext{
${ }^{87}$ Vid. CONAPACH, “Informe Alternativo 2010 respecto...”, cit., pp. 53 y 54.

${ }^{88}$ En este sentido se han pronunciado los órganos de control normativo de la OIT, como explica el relator Anaya, que han concebido la consulta como un “"verdadero instrumento de participación', que debe responder al objetivo último de establecer un diálogo entre las partes basado en principios de confianza y respeto mutuos, y con miras a alcanzar un consenso entre las mismas", relator especial de Naciones Unidas, ANAYA, J., "Principios Internacionales...", cit., párr. 23.

${ }^{89}$ El artículo 14 , inciso $3^{\circ}$, del Reglamento establece que se debe entender por medidas administrativas "las nuevas políticas, planes y programas, con excepción de aquellos contemplados en el artículo 21 de este reglamento, elaboradas por los órganos de la administración del Estado señalados en el art. 4 del presente reglamento, que afecten directamente a los pueblos indígenas". El artículo 21 señala la pertinencia de la consulta: "Para la formulación, aplicación y evaluación de planes y programas de desarrollo nacional o regional susceptibles de afectar directamente a los pueblos indígenas, la autoridad $\mathrm{u}$ organismo respectivo deberá analizar con el Ministerio de Planificación Nacional y en coordinación con el Ministerio Secretaría General de la Presidencia, la pertinencia de iniciar el proceso de participación establecido en el art. 3 de este reglamento". Artículos 14, incisos 3 y 21, del Reglamento del artículo 34 de la Ley $\mathrm{N}^{\circ} 19.253$, creado por el Decreto Supremo $\mathrm{N}^{\circ} 124$.

${ }^{90}$ Comisión de Expertos en Aplicación de Convenios de la OIT -CEACR - (2011, 16 de febrero), Informe de la Comisión de Expertos en Aplicación de Convenios y Recomendaciones (artículos 19, 22 y 35 de la Constitución). Tercer punto del orden del día: Informaciones y memorias sobre la aplicación de convenios y recomendaciones. ILC.100/III/1 ${ }^{\mathrm{a}}$, Conferencia Internacional del Trabajo, 100. a reunión, 2011. $\begin{array}{lllllll}\text { Recuperado el } & 2 & \text { de } & \text { septiembre } & \text { de } & 2011 & \text { de: }\end{array}$ 〈http://www.ilo.org/public/libdoc/ilo/P/09663/09963\%282011-100-1A\%29.pdf〉.
} 
En dicho documento la CEACR rechaza tácitamente ${ }^{91}$ la primera Memoria Oficial del Gobierno de Chile sobre la implementación del Convenio presentada ante la OIT, esencialmente por el hecho de que su contenido contrasta altamente con los informes alternativos emanados de diversas organizaciones y asociaciones de trabajadores ligadas al mundo indígena ${ }^{92}$ que ponen en evidencia la falta de diálogo y la nula implementación de las reformas legales y administrativas necesarias para adecuar el ordenamiento jurídico a las nuevas obligaciones emanadas del Convenio.

La Memoria del Gobierno fue presentada al filo del plazo de entrega (septiembre de 2010) sin haber pasado por el trámite de consulta ni haberse informado previamente a los pueblos indígenas, vulnerando por sí misma el espíritu de publicidad, colaboración y entendimiento del Convenio. En atención a todas estas circunstancias, que evidencian un inexistente cumplimiento del Convenio 169, la CEACR consideró que Chile deberá ser examinado nuevamente en 2011 sobre la materia.

Ante este panorama, el Gobierno decidió impulsar a través del Ministerio de Planificación y Cooperación (MIDEPLAN) un nuevo procedimiento de consulta y participación con objeto de superar la "provisionalidad" del Decreto 124 y establecer una "Nueva Institucionalidad Indígena”. Para ello, en marzo de 2011 notificó el inicio de un proceso de consultas que además incluía una serie de temas de capital importancia como el reconocimiento constitucional de los pueblos indígenas, la creación del Consejo de Pueblos Indígenas, la aprobación del nuevo Reglamento del Servicio de Evaluación de Impacto

\footnotetext{
${ }^{91}$ El Informe CEACR señala textualmente: "La Comisión toma nota de la detallada primera memoria y de los completos anexos proporcionados por el Gobierno, que demuestran la atención particular que éste brinda a la aplicación del Convenio. La Comisión toma nota asimismo de los comentarios de la Confederación Nacional de Pescadores Artesanales de Chile (CONAPACH), y de la Central Unitaria de Trabajadores de Chile (CUT) en nombre de la Coordinación de Organizaciones y Comunidades Mapuches, Región de la Araucanía y del Centro de Cultura Pueblos Nación Mapuche Pelón Xaru, ambos de 30 de agosto de 2010, así como de los comentarios de la CUT de 1. ${ }^{\circ}$ de octubre de 2010. La Comisión toma nota asimismo de los comentarios presentados por la Confederación Nacional de Sindicatos de Trabajadores Panificadores (CONAPAN) el 3 de noviembre de 2010. La Comisión examinará estas comunicaciones en su próxima reunión junto con toda observación que el Gobierno desee presentar al respecto. La Comisión pide al Gobierno que responda a los comentarios de la CONAPACH, de la CUT y de CONAPAN [negritas en el original]. // La Comisión plantea otros puntos en una solicitud dirigida directamente al Gobierno". Comisión de Expertos en Aplicación de Convenios de la OIT CEACR—, "Informe de la Comisión...", cit., p. 868.

${ }^{92}$ Vid. nota 47 supra.
} 
Ambiental (SEIA) y la señalada determinación de un nuevo procedimiento de consulta y participación, entre otros ${ }^{93}$.

Paradójicamente, el Gobierno determinó efectuar este proceso de consulta a los pueblos indígenas no por las normas determinadas por el Convenio 169, sino de acuerdo con las establecidas por el Decreto $\mathrm{N}^{\circ} 124$ de MIDEPLAN, vulnerando nuevamente los estándares del Convenio en materias de especial sensibilidad para los pueblos originarios. Ello originó protestas indignadas de algunos sectores de la sociedad civil y de los colectivos y las comunidades indígenas, lo que acarreó la solicitud de paralización del proceso de consultas.

Ante esta situación, la Comisión de Derechos Humanos de la Cámara de Diputados de Chile, en sesión del 15 de junio de 2011, acogió un planteamiento de diversas organizaciones de los pueblos indígenas para derogar el Decreto 124/2009 por constituir una barrera a la regulación de la participación y consulta de los pueblos indígenas en la normativa ambiental y acordó solicitar la derogación del citado Decreto. Con posterioridad, el 3 de agosto de 2011 el Senado aprobó un proyecto de acuerdo para solicitar la suspensión de la consulta sobre la nueva institucionalidad indígena y la derogación del Decreto 124, trámite que al término de este estudio se encuentra pendiente ${ }^{94}$.

Finalmente, el 1 de septiembre el nuevo ministro de Planificación reconoció el fracaso del proceso de consulta sobre la nueva institucionalidad y anunció su suspensión, aunque señaló que el Decreto $\mathrm{N}^{\circ} 124$ continuará vigente hasta que se determine un mecanismo de consulta definitivo adecuado y que haya sido consensuado con los pueblos indígenas ${ }^{95}$.

\footnotetext{
${ }^{93}$ Vid. Plan de Consulta sobre Institucionalidad Indígena en http://www.consultaindigena.cl/munitas/Plan de Consulta.pdf. Pueden consultarse las minutas explicativas sobre las reformas a la nueva institucionalidad indígena en http://www.consultaindigena.cl/minutas.html.

${ }^{94}$ Senado Chile (2011, 3 de agosto). Boletín núm. S 1.378-12, "Proyecto de acuerdo de los Honorables Senadores señores Navarro, Girardi, Gómez, Lagos y Quintana, sobre consultas indígenas en el marco del Convenio No 169 de la OIT". Recuperado el 24 de septiembre de 2011 de http://www.politicaspublicas.net/panel/images/stories/docs/2011-senado-proyecto-acuerdo-dec-124.pdf.

95 El 14 de septiembre de 2011 el Consejo Nacional de la Corporación Nacional de Desarrollo Indígena de Chile (CONADI) decidió crear una comisión cuyo objetivo será proponer un mecanismo para comenzar una nueva etapa de la consulta en conjunto con personeros de Gobierno y expertos internacionales en el tema indígena. Las noticias sobre el desarrollo del proceso de consulta pueden consultarse en el sitio web sobre consulta indígena del Gobierno de Chile, en http://www.consultaindigena.cl/index-primera-etapa.html.
} 


\section{CONCLUSIONES}

La implementación del derecho de consulta del Convenio $\mathrm{N}^{\circ} 169$ de la OIT a través del Decreto Supremo 124 que creó el Reglamento de consulta y participación del artículo 34 de la Ley Indígena ha sido un verdadero fraude al Convenio. A lo largo del presente estudio hemos podido constatar las innumerables trasgresiones, tanto formales como de fondo, a los estándares mínimos fijados por el derecho internacional de los pueblos indígenas para la implementación del derecho de consulta, "piedra angular" del Convenio.

Urgen modificaciones sectoriales ambientales en materias tales como el SEIA, el régimen de aguas, la Ley de Pesca, la minería o la legislación forestal, para adecuar la normativa ambiental a las nuevas exigencias de participación y consulta emanadas de los estándares internacionales del derecho de los pueblos indígenas, en especial del Convenio 169, con el objeto de prevenir la ocurrencia de conflictos normativos que redunden en perjuicio de los pueblos indígenas y los proyectos de inversión, y que a la larga signifiquen la responsabilidad internacional ulterior del Estado.

La reforma de la institucionalidad ambiental ofrecía una inmejorable oportunidad para, a la luz de la entrada en vigor del Convenio, aumentar los espacios de participación y consulta en procedimientos de toma de decisiones de los órganos competentes del Estado en materia ambiental en actuaciones con incidencia sobre intereses de los pueblos originarios, pero se dejó escapar la oportunidad.

A la fecha, salvo la introducción en el inciso $2^{\circ}$ del artículo 4 de la Ley de Bases Generales de Medio Ambiente No 19.300 de la directriz normativa de carácter general que establece la obligación para los órganos del Estado, en el ejercicio de sus competencias ambientales y en la aplicación de los instrumentos de gestión ambiental, de propender por la adecuada conservación y protección de los pueblos indígenas de conformidad con lo señalado en la ley y en los convenios internacionales ratificados por Chile, nada significativo se ha hecho en el derecho positivo.

La esperanza de abrir los espacios de participación e inclusión de nuestros pueblos originarios en la determinación del modelo de desarrollo y la protección del medio ambiente en un contexto multicultural está depositada en una adecuada implementación del derecho a la consulta del Convenio $\mathrm{N}^{\circ} 169$. Una de las primeras tareas en tal sentido deberá ser la derogación del Decreto 124/2009 que hemos analizado a lo largo de este 
trabajo, por constituir una barrera a la regulación de la participación y consulta de los pueblos indígenas en la normativa ambiental, para luego determinar un procedimiento adecuado conforme a los estándares internacionales del derecho de los pueblos indígenas. El proyecto de Nuevo Reglamento del SEIA, que aún no se ha aprobado y que deberá pasar el trámite de consulta previa de buena fe por parte de los pueblos originarios, puede ser uno de los primeros pasos en esa dirección.

\section{BIBLIOGRAFÍA}

\section{Libros y artículos}

ANAYA S., J., Los Pueblos indígenas en el derecho internacional, Trotta, Madrid, 2004.

APARICIO WILHELMI, M., Los Pueblos indigenas y el Estado: el reconocimiento constitucional de los derechos indígenas en América Latina, Cedecs, Barcelona, 2002.

BERRAONDO LÓPEZ, M., "Derecho humano al medio ambiente y pueblos indígenas. Dos derechos con un mismo fin”, Mariño Menéndez, F., Oliva Martínez, D. (eds.), Avances en la protección de los derechos de los pueblos indígenas, Dykinson, Madrid, 2004.

CLAVERO SALVADOR, B. (2009, 18 de septiembre), "Puesta en Práctica de Convenio o Puesta en Evidencia de Chile (Por los Informes del Relator Anaya)". Recuperado el 28 de agosto de 2011 de: $<$ http://clavero.derechosindigenas.org/?p=3313> .

DÍAZ-POLANCO, H., Autonomía regional. La autodeterminación de los pueblos indios, Siglo XXI editores, segunda edición aumentada, México, 1996.

GAETE GONZÁLEZ, E., "Derecho Internacional y Derechos de los Estados: incorporación de los derechos humanos”, Revista Chilena de Derecho, vol. 23, núms. 2 y 3, tomo I, 1996.

KÖNIG, H., “¿Bárbaro o símbolo de la libertad? ¿Menor de edad o ciudadano? Imagen del indio y política indigenista en Hispanoamérica”, König, Hans-Joachim (ed.), El 
indio como sujeto y objeto de la historia latinoamericana. Pasado y presente, Vervuert Verlag, Iberoamericana, Madrid, 1998.

MARTÍNEZ DE PISÓN, J., Políticas de Bienestar. Un estudio sobre los derechos sociales, Tecnos, Madrid, 1998.

MEZA-LOPEHANDÍA, M. (2009), "El reglamento sobre consulta a pueblos indígenas propuesto por el Gobierno de Chile, la buena fe y el derecho internacional de los Derechos Humanos". Recuperado el 2 de septiembre de 2011 de: $<$ http://www.mapuexpress.net/images/publications/13_10_2009_21_55_57_1.pdf $>$.

MONTT OYARZÚN, S., y MATTA AYLWIN, M., "Una visión panorámica al Convenio OIT 169 y su implementación en Chile", Estudios Públicos núm. 121, verano 2011.

PRECHT RORRIS, A., y AYLWIN CORREA, S., "Entrada en vigencia del Convenio 169: El proceso de consulta de los pueblos indígenas y los proyectos sometidos al SEIA”, Durán Medina, V., et ál. (eds.), Derecho ambiental, en tiempos de reformas. Actas de las V Jornadas de Derecho Ambiental, Abeledo-Perrot, Santiago, 2010.

RODRÍGUEZ-PIÑERO ROYO, L., "La OIT y los pueblos indígenas en el derecho internacional: del colonialismo al multiculturalismo", Aparicio Wilhelmi, M. (coord.), Caminos hacia el reconocimiento: pueblos indigenas, derechos y pluralismo / Camins cap al reconeixement: pobles indígenes, drets i pluralisme. Servei de Publicacions de la Universitat de Girona, Girona, 2005.

RUIZ-RICO RUIZ, Gerardo, El derecho constitucional al medio ambiente, Tirant lo Blanch, Valencia, 2000.

STAVENHAGEN, R., "Derecho Internacional y derechos indígenas", en Krotz, E., Antropología Jurídica: Perspectivas socioculturales en el Estudio del Derecho, Antropos-UAM, Barcelona, 2002.

TOLEDO LLANCAQUEO, V. (2009), "Texto comentado del Decreto 124 de 'Reglamento de Consulta y Participación de los pueblos indígenas en Chile"”. Recuperado el 28 de agosto de 2011 de: $<$ http://www.politicaspublicas.net/panel/imp/392-decreto-124.html $>$.

VERDUGO, M., PFEFFER, E., y NOGUEIRA, H., Derecho Constitucional, tomo I, $2^{\mathrm{a}}$ edición, Editorial Jurídica de Chile, Santiago, 2005. 
YRIGOYEN FAJARDO, R., "Hitos del Reconocimiento del pluralismo jurídico y el derecho indígena en las políticas indigenistas y el constitucionalismo andino", Berraondo, M. (coord.), Pueblos Indigenas y derechos humanos, Universidad de Deusto, Bilbao, 2006

\section{Informes y recomendaciones}

Biblioteca del Congreso Nacional de Chile, Historia de la Ley Decreto $N^{0}$ 236, Ministerio Relaciones Exteriores, Promulga el Convenio N 169 sobre Pueblos Indígenas y Tribales en Países Independientes de la Organización Internacional del Trabajo. Recuperado el 11 de agosto de 2011 de: $<$ http://www.bcn.cl/obtienearchivo?id=recursoslegales/10221.3/538/3/hdl-236.pdf $>$.

Comisión de Derechos Humanos, Nacionalidad y Ciudadanía (1991, 12 de marzo), "Informe de la Comisión de Derechos Humanos, Nacionalidad y Ciudadanía, recaído en el Proyecto de Acuerdo que aprueba el Convenio $\mathrm{N}^{\mathrm{o}} 169$ sobre Pueblos Indígenas y Tribales en Países Independientes”, Boletín núm. 233-10 (I), en Biblioteca del Congreso Nacional de Chile, Historia de la Ley Decreto No 236, Ministerio Relaciones Exteriores, Promulga el Convenio $\mathrm{N}^{\mathrm{o}} 169$ sobre Pueblos Indígenas y Tribales en Países Independientes de la Organización Internacional del Trabajo. Recuperado el 11 de agosto de 2011

de:

$<$ http://www.bcn.cl/obtienearchivo?id=recursoslegales/10221.3/538/3/hdl-236.pdf $>$.

Comisión de Expertos en Aplicación de Convenios de la OIT —CEACR - (2011, 16 de febrero), "Informe de la Comisión de Expertos en Aplicación de Convenios y Recomendaciones (artículos 19, 22 y 35 de la Constitución). Tercer punto del orden del día: Informaciones y memorias sobre la aplicación de convenios y recomendaciones". ILC.100/III/1 a, Conferencia Internacional del Trabajo, 100. reunión, 2011. Recuperado el 2 de septiembre de 2011 de: $<$ http://www.ilo.org/public/libdoc/ilo/P/09663/09963\%282011-100-1A\%29.pdf>.

Comisión de Expertos en Aplicación de Convenios y Recomendaciones (2009), "Informe de la Comisión de Expertos en Aplicación de Convenios y Recomendaciones”, CEACR 2009/98a reunión. Recuperado el 2 de septiembre de 2011 de: $<\mathrm{http}$ //www.ilo.org/wcmsp5/groups/public/---ed_norm/--relconf/documents/meetingdocument/wcms_103488.pdf $>$. 
CONAPACH (2010, 1 de septiembre), "Informe Alternativo 2010 respecto del cumplimiento del Convenio 169 sobre Pueblos Indígenas y Tribales de la OIT, al cumplirse un año de su entrada en vigencia en Chile”. Recuperado el 1 de septiembre de 2011 de: <http://www.derechoshumanos.udp.cl/wp-content/uploads/2010/10/memoriaalternativa-convenio-169-oit-chile-2010-1.pdf>.

Corte Interamericana de Derechos Humanos, caso de la Comunidad Mayagna (Sumo) Awas Tingni contra Nicaragua, Sentencia de 31 de agosto de 2001 (Fondo, Reparaciones y Costas), párrafo 149. Recuperado el 12 de agosto de 2011 de: $<$ http://www.corteidh.or.cr/docs/casos/articulos/Seriec_79_esp.pdf $>$.

GOBIERNO DE CHILE (2010, 1 de septiembre), "Memoria presentada por el Gobierno de Chile en conformidad con las disposiciones del artículo 22 de la Constitución de la Organización Internacional del Trabajo correspondiente al período de 15 de septiembre de 2009 al 15 de septiembre de 2010 acerca de las medidas adoptadas para dar efectividad a las disposiciones del Convenio sobre Pueblos Indígenas y Tribales, 1989 (NÚM. 169), ratificado por Chile el 15 de septiembre de 2008”. Recuperado el 1 de septiembre de 2011 de: <http://www.derechoshumanos.udp.cl/wpcontent/uploads/2010/10/memoria-oficial-convenio-169-oit-1c2b0-septiembre2010.pdf $>$.

Instituto Nacional de Derechos Humanos (2010), “Informe Anual 2010: Situación de los Derechos Humanos en Chile". Recuperado el 1 de septiembre de 2011 de: $<$ http://www.indh.cl/primer-informe-anual-2010-de-derechos-humanos-en-chile> .

Organización de Estados Americanos OEA, Comisión Interamericana de Derechos Humanos CIDH (2009, 30 de diciembre), "Derechos de los pueblos indígenas y tribales sobre sus tierras ancestrales y recursos naturales. Normas y jurisprudencia del Sistema Interamericano de Derechos Humanos", OEA/Ser.L/V/II. Doc. 56/09. Recuperado el 11 de agosto de 2011 de: <http://cidh.org/countryrep/TierrasIndigenas2009/TierrasAncestrales.ESP.pdf $>$.

Relator especial de Naciones Unidas sobre la situación de los derechos humanos y las libertades fundamentales de los indígenas, ANAYA, J. (2009, 15 de julio), "Informe del Relator Especial sobre la situación de los derechos humanos y las libertades fundamentales de los indígenas", presentado al Consejo de Derechos Humanos, $12^{\circ}$ 
período de sesiones, A/HRC/12/34. Recuperado el 8 de septiembre de 2011 de: $<$ http://unsr.jamesanaya.org/esp/docs/annual/2009_hrc_annual_report_sp.pdf $>$.

Relator especial de Naciones Unidas sobre la situación de los derechos humanos y las libertades fundamentales de los indígenas, ANAYA, J. (2009, 24 de abril), "Principios Internacionales aplicables a la consulta en relación con la Reforma Constitucional en materia de Derechos de los Pueblos Indígenas en Chile”. Recuperado el 8 de septiembre de 2011 de:

$<$ http://unsr.jamesanaya.org/esp/docs/special/2009_special_chile_informeconsulta_abril 09_sp.pdf $>$.

Relator especial de Naciones Unidas sobre la situación de los derechos humanos y las libertades fundamentales de los indígenas, ANAYA, J. (2009, 14 de septiembre), "La situación de los Pueblos Indígenas en Chile: seguimiento de las recomendaciones hechas por el Relator anterior", A/HRC/12/34/Add.6, recuperado el 8 de septiembre de 2011 de: <http://unsr.jamesanaya.org/esp/docs/countries/2009_report_chile_sp.pdf $>$.

Senado Chile (2011, 3 de agosto). Boletín núm. S 1.378-12, "Proyecto de acuerdo de los Honorables Senadores señores Navarro, Girardi, Gómez, Lagos y Quintana, sobre consultas indígenas en el marco del Convenio No 169 de la OIT”. Recuperado el 24 de septiembre de 2011 de:

$<$ http://www.politicaspublicas.net/panel/images/stories/docs/2011-senado-proyectoacuerdo-dec-124.pdf>.

\section{Legislación y jurisprudencia}

Corte de Apelaciones Temuco, Rol N 1705-2009. Caso Puelman Nanco Mariano y otro contra Comisión Regional del Medio Ambiente Región de la Araucanía,

Decreto $N^{0}$ 236, de 2 de octubre de 2008, del Ministerio de Relaciones Exteriores de Chile, que promulga Convenio $\mathrm{N}^{\mathrm{0}} 169$ sobre Pueblos Indígenas y Tribales en Países Independientes de la Organización Internacional del Trabajo (DO 14/10/2008).

Decreto Supremo $N^{\circ} 124$ que reglamenta el artículo 34 de la Ley $\mathrm{N}^{\circ} 19.253$ a fin de regular la consulta y la participación de los pueblos indígenas (DO 25/09/2009). 
Ley $\mathrm{N}^{\circ} 19.253$, que establece normas sobre protección, fomento y desarrollo de los indígenas, y crea la Corporación Nacional de Desarrollo Indígena (DO 05/10/1993).

Ley $\mathrm{N}^{\circ}$ 20.417, que crea el Ministerio, el Servicio de Evaluación Ambiental y la Superintendencia del Medio Ambiente (DO 26/01/2010).

Ley No 19.300 de Bases Generales del Medio Ambiente (DO 09/03/1994).

Reglamento del artículo 34 de la Ley $N^{\circ} 19.253$, creado por el Decreto Supremo $\mathrm{N}^{\circ}$ 124.

Sentencia Rol 1050, 03/04/2008. Control de constitucionalidad del proyecto de acuerdo aprobatorio relativo al Convenio $\mathrm{N}^{\mathrm{o}} 169$ sobre Pueblos Indígenas, adoptado por la Organización Internacional del Trabajo, de 27 de junio de 1989.

Tribunal Constitucional, Fallo 309, año 2000.

Tribunal Constitucional, Sentencia Rol No 309, de 4 de agosto de 2000. 